\title{
Economic Impacts of Irrigation-Constrained Agriculture in the Lower Po Basin
}

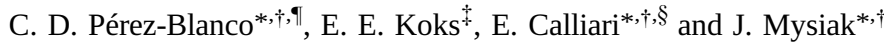 \\ *Fondazione Eni Enrico Mattei (FEEM). Isola di \\ San Giorgio Maggiore, 8. 30124 Venice, Italy \\ †Centro Euro-Mediterraneo sui Cambiamenti Climatici (CMCC) \\ RAAS Division. Isola di San Giorgio Maggiore \\ 8. 30124 Venice, Italy \\ Institute for Environmental Studies (IVM) \\ VU University, Amsterdam, The Netherlands \\ $\S_{\text {Università Ca’ Foscari, Department of Economics }}$ \\ Cannaregio 873, 30121 Venice, Italy \\ dionisio.perez@feem.it
}

Received 26 October 2016

Revised 19 January 2017

Accepted 9 February 2017

Published 10 May 2017

\begin{abstract}
Climate change, increasing demand for water, higher environmental standards and inelastic water supply suggest that future drought response in Southern Europe would require more efficient management of water use. In this context, there is a pressing need for a better understanding of the economic impacts of irrigation restrictions, including their microeconomic and broad economic repercussions. This paper connects a multi-attribute Revealed Preference Model working at an agricultural district level with a regionally calibrated supply and use model that combines nonlinear programming and input-output modeling techniques to address water allocation issues. To the best of our knowledge, this is the first time these two modeling approaches are combined in this fashion. Methods are illustrated with an application to the Lower Po River Basin (LPRB) in the Emilia Romagna Region, Italy. Results show that irrigation restrictions generate rising incremental losses in the agricultural districts of the LPRB, which are amplified through negative inter-sectorial feedbacks at a regional level. Contraction of production in Emilia Romagna results in an excess demand situation that propels the production of substitute goods elsewhere in Italy, partially but not fully
\end{abstract}

This is an Open Access article published by World Scientific Publishing Company. It is distributed under the terms of the Creative Commons Attribution 4.0 (CC-BY) License. Further distribution of this work is permitted, provided the original work is properly cited. 
compensating economic losses in the region. Methods and results offer a basis for assessing tradeoffs in irrigation restrictions and related adaptations, for climate change included.

Keywords: Mathematical programming; input-output modeling; irrigation restrictions; Po River Basin.

\section{Introduction}

Southern Europe is becoming drier. A hotter and more volatile climate will reduce rain-fed crop yields, and farmers are likely to extend irrigation while seeking to adapt. With high confidence, water demand for irrigating crops is expected to increase by more than $40 \%$ by 2080 (IPCC 2014), accelerating the observed expansion in irrigation infrastructure over the past 50 years (EEA 2009). Declining average water availability will be insufficient to meet the growing irrigation demand (IPCC 2014). More frequent and intense droughts (EC 2012) will further aggravate the supplydemand imbalance, and so will the more stringent environmental (e.g., ecological flow) standards (EC 2000). As the competition among economic water uses tightens up, and the costs of exploiting new water sources increase, it is generally expected that water restrictions and rationing will be put in place more often (OECD 2014). In this context, there is a pressing need to better understand the economic impacts of irrigation restrictions, including their micro- and macro-economic implications (UN 2016). Decision support systems, notably systems analysis, could play a useful role in this regard. Building on recent advances in systems analysis, this research develops a modeling framework that captures the rationale behind farmers' behavior and responses, and represents the complex interactions among sectors and regions within an economy, with the aim of predicting both the local and broad economic repercussions of irrigation constraints.

Systems analysis has become in recent decades an increasingly important tool for supporting water resources management (Girard et al. 2015). Systems analysis captures interconnections between elements of a system, thus allowing the use of a logical procedure involving mathematical constructs to model supply-demand interplay for assessing the costs and benefits of alternative management strategies, following agronomic, hydrological or economic criteria, or a combination thereof (hybrid approaches, e.g., hydro-economic) (Feldman 1992; Harou et al. 2009; Singh 2012). Economic objectives and constraints have been used in systems analysis since the 1960s (Maass et al. 1962), and have gained importance ever since. The increasing

prominence of economics in water resources management came as a reaction to the incremental costs of conventional engineering approaches, which eventually led to inelastic water supply in several basins and called for a better understanding and representation of the water demand dynamics and its drivers (Randall 1981). 
Two categories of economic models are typically used in water resources management: micro- and macroeconomic. Microeconomic modeling analyzes the pattern of yields, revenues and costs at a farm or (agricultural/irrigation) district scale (representative farmer). Farmers' decisions determine crop mix and timing, water application and (investments in) capital stock, to optimize ${ }^{1}$ farm performance with respect to a single or multiple objectives, within a domain defined by a number of constraints. Most models rely on single-attribute objective functions that maximize the utility derived from profit. This is the case of Expected Utility (ExU), Linear Programming (LP) and Positive Mathematical Programming (PMP). However, single-attribute utility functions appear to be inconsistent with observed farmers' behavior and the Theory of Planned Behavior (TPB), suggesting that decision-making is driven by multiple attributes of objects (including but not limited to profit) and farmers’ beliefs (Läpple and Kelley 2013; Poppenborg and Koellner 2013). Normative ExU models also present issues with ex-post validation that have prompted criticism (Rabin and Köszegi 2007; Rabin and Thaler 2001). Notably, Chambers and Quiggin (2000) have argued that the standard approach to represent choice under uncertainty is "inflexible and, in important respects, unrealistic,” and propose using models that rely on the state-contingent notion (see e.g., Adamson et al. 2007; Adamson and Loch 2014; Mallawaarachchi et al. 2008). Inductive LP and PMP models, on the other hand, present problems with calibration. LP demands many constraints that often lead to corner solutions or abrupt discontinuities in agents' responses, and attempts to avoid overspecialization introducing additional restrictions (McCarl 1982) that result in "overly constrained” models (Graveline 2016). PMP models address this shortcoming through dual variables of calibration constraints to "specify a non-linear objective function such that observed activity levels are reproduced by the optimal solution" (Heckelei and Britz 2005); yet, the economic or technological rationale behind the nonlinear terms in the objective function remains unclear and does not inform on the drivers behind observed choices (Heckelei et al. 2012).

By building on the axioms of revealed preference (Houthakker 1950; Samuelson 1938), it is possible to construct Revealed Preference Models (RPM) that are both consistent with observed choices and suitable as a basis for empirical analysis - thus addressing the tradeoff between the model's capability to deliver numerical results for policy evaluation and its coherence with economic theory and principles (Afriat 1967; Diewert 1973). RPM also feature multi-attribute objective

\footnotetext{
${ }^{1}$ An alternative to optimization is simulation. However, the usual approach to solving water management problems by means of economics is optimization (Graveline 2016; Harou et al. 2009; Singh 2012).
} 
functions that are consistent with ex-post evidence and the TPB (Gómez-Limón et al. 2016). Although revealed preference principles have been mostly used in economic theory (Varian 2006), empirical analyses have been conducted for decades now (Varian 2012). The seminal work by Gutiérrez-Martín and Gómez (2011) has applied revealed preference principles to water resources management and farm modeling, and a number of applications have since been developed (Gutiérrez-Martín et al. 2014; Pérez-Blanco et al. 2016, 2015).

Macroeconomic modeling examines dynamics of aggregate quantities such as goods and services produced, income, capital employment, and prices at the regional (Carrera et al. 2015; Dixon et al. 2011), national (Bosello et al. 2012; Ciscar et al. 2011) and global levels (Hertel 1997; Lenzen et al. 2013). The two most commonly used models for assessing the broad economic impacts of environmental changes are Computable General Equilibrium (CGE) and Input-Output (IO) models. In CGE models, agent behavior is calibrated from observed economic flows registered in Social Accounting Matrices. These models often follow a Walrasian framework, where investments are saving-driven and agents minimize private expenditure to attain a given utility level. Competition for water can be represented either implicitly (irrigated land, which itself embodies water) or explicitly. The latter approach is used, e.g., by Darwin et al. (1995) for the US, although replication of this approach elsewhere can be challenging due to limited information on water use, value and prices. On top of that, the shadow price of water may not meet the gap between irrigated and rain-fed production to pay for the returns to water. Accordingly, in Berrittella et al. (2007), irrigated land production is represented by using a nested Constant Elasticity of Substitution (CES) function in which water and other inputs enter in a fixed proportion. Water demand responds to a water rent, which in turn derives from supply constraints. Calzadilla et al. (2011) use a more flexible three-level CES production function, which allows for different degrees of substitutability between inputs at each level and permits two ways of reallocating water: substituting other inputs for water and reducing demand for water intensive products. Yet, since rain-fed and irrigated production appear as part of the same aggregate national production function, it is not possible to stop irrigating an area in favor of rain-fed agriculture - a major weakness that complicates policy assessment (e.g., irrigation restrictions).

IO models, on the other hand, reflect the economic interdependencies between sectors and regions within an economy, through intermediate supply and final demand, based on linear relations (Koks et al. 2015). Linear IO models applied to water typically combine input-output matrices and water accounts and apply a structural decomposition analysis that disaggregates the effects of a given shock on 
economic outputs and water use at different levels, from urban (Wang et al. 2009) to multi-regional (Wan et al. 2016). Because of their descriptive nature, researchers have frequently resorted to IO models to determine which sectors consume more water (directly and indirectly) (Bogra et al. 2016), estimate their productivity (apparent and induced) (Duarte et al. 2002), assess their exposure and vulnerability to shortages (Zhao et al. 2015), and support the design of water and agricultural policy (González 2011; Llop 2008). Despite much progress, linear IO models still tackle two major issues insufficiently: (i) disruptions, such as droughts, are most often a disruption in the supply-side of the production chain; and (ii) modeling the substitution capabilities of other regions and/or other industries. Nonlinear optimization has been combined with IO modeling techniques to overcome these issues, thus providing the simplicity of IO modeling (i.e., Leontief production function) while allowing for some more flexibility (Baghersad and Zobel 2015; Oosterhaven and Bouwmeester 2016). One such approach can be found in the MultiRegional Impact Assessment (MRIA) model (Koks and Thissen 2016). With the use of the MRIA model, the first aforementioned issue is tackled by using optimization techniques to solve the model, which allows for taking endogenous import and supply constraints into account in an essentially demand-determined model. This overcomes two potential concerns: (i) the need for translating the supply-side shock into a demand-side shock and (ii) the need for using a supplydriven IO model. The second issue is tackled by introducing (multiregional) substitution possibilities, i.e., allowing products to be produced by different industries in the same or other regions. This approach allows for an endogenously determined new post-disaster optimum with shifts between main suppliers within the boundaries of the existing (trade and) production structure of the (regional) economy.

Micro- and macroeconomic concepts can be operationalized in systems analysis through stand-alone economic models or hybrid models. Most hybrid models combine microeconomic and engineering models by using a holistic or modular approach (Harou et al. 2009). Holistic approaches typically represent farmer behavior by using piecewise exogenous benefit functions that relate water use to profit, and then solve both models together to represent causal relationships and interdependencies. Modular approaches run the two models independently in a recursive or sequential fashion, which increases the probability of convergence on an optimal solution and the level of detail in each sub-field (Heinz et al. 2007; Singh 2012). Computationally demanding macroeconomic models are typically run independently, and combined with other models (e.g., engineering models) using a modular approach (see e.g., Grames et al. 2016). Although micro- and 
macroeconomic models have been widely used to inform drought management, water management typically relies on one or the other, and connected micro- and macroeconomic models are rare (Pérez-Blanco et al. 2016). This leaves the policy-maker facing a choice between two models offering complementary outputs.

One obvious solution to this tradeoff is to solve both models independently, where available, and use their outputs to inform water policy. This may not be as straightforward as it seems since the foundations of both approaches (individual behavior in narrowly defined markets versus structure and behavior of a whole economy) can lead to conflicting results (Pindyck 2015). Using a holistic approach to nest micro- and macroeconomic models is challenging, as the two follow their own internal optimization procedures, and making them compatible may demand oversimplification (e.g., piecewise functions) (Harou et al. 2009). This paper presents a methodological framework that utilizes a modular approach to connect, in a sequential fashion, a multi-attribute RPM with a macroeconomic MRIA model. To the best of our knowledge, this is the first time the two models are connected in this fashion. The methods presented in this paper aim to offer policy makers a policy assessment tool that combines the advantages of the two models while guaranteeing consistency. Figure 1 presents a diagram that describes the two models and how they are connected.

This modeling framework is used to assess the microeconomic and broad economic impacts of seasonal irrigation restrictions in two stages: in the first stage, the multi-attribute RPM is calibrated and a series of simulations is run to estimate

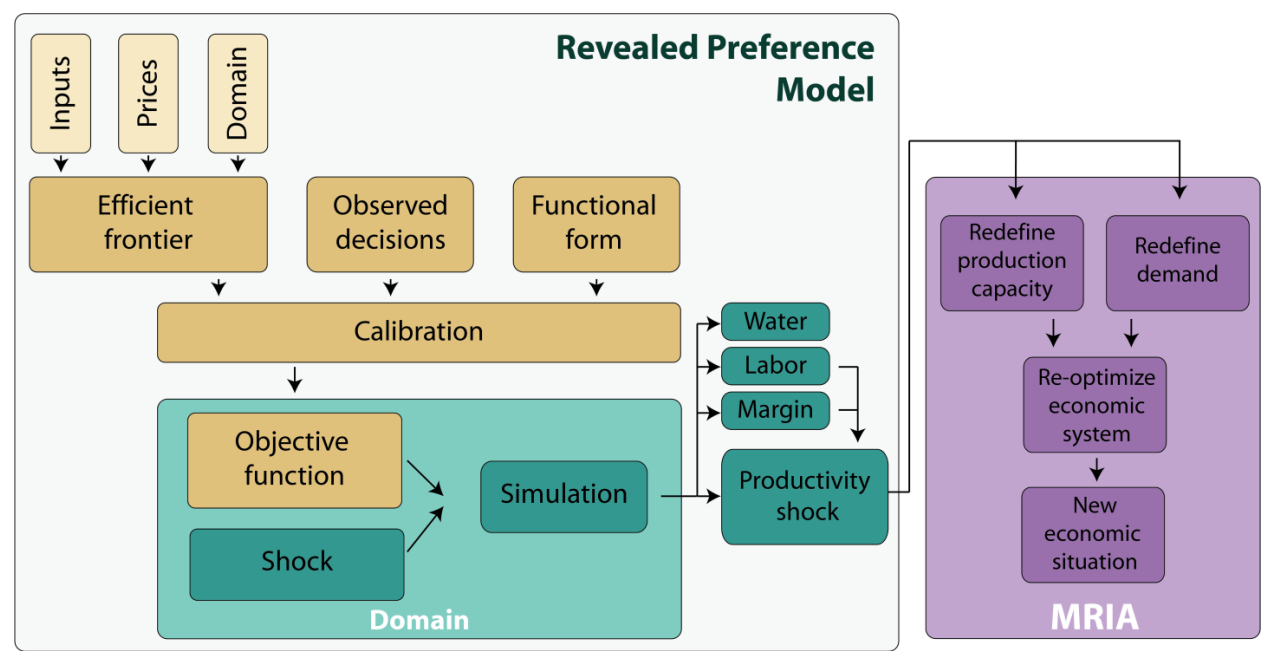

Figure 1. The Modeling Framework 
the impacts of irrigation restrictions on the income of farmers; in the second stage, estimated income impacts are adapted and imported into the MRIA model to calculate the broad economic repercussions across sectors and regions. The exercise is illustrated with an application to the Lower Po River Basin (LPRB) in northeastern Italy. Despite its growing drought exposure and inflating agricultural losses (PRBDA 2015), drought management in the Po River Basin has hitherto been informed through a hydrological model that does not include information on the economic impact of irrigation restrictions. This may be leading to inappropriate drought responses (Mysiak et al. 2014). By means of a thorough representation of farmers' preferences, related responses and their broad economic repercussions, this research can be used to estimate the abatement costs of droughts. Authors intend to leverage on this research and its outcomes, in order to strengthen ongoing collaboration with basin authorities and explore the development of a hydro-economic model based on sound micro- and macroeconomic principles. ${ }^{2}$

\section{The Lower Po River Basin, Italy}

The LPRB is located at the northeast area of the Italian Peninsula. It comprises the mid- and downstream part of the Po River and its sub-basins Trebbia, Nure, Chiavenna, Arda-Ongina, Taro, Parma, Enza, Crostolo, Secchia and Panaro. The LPRB spreads throughout the administrative provinces Piacenza, Parma, Reggio Emilia (entirely); Modena, Ferrara (most of its territory); and Bologna (marginally) in the Emilia Romagna Region; and the southernmost part of the Veneto Region ${ }^{3}$ (see Fig. 1). The LPRB comprises the Po Delta Nature Park, a biosphere reserve of UNESCO's Man and the Biosphere Programme, and a World Heritage site (UNESCO 1999). Irrigated areas are comprised in 30 Agricultural Districts (ADs) (see Fig. 2). ADs are clusters of municipalities with similar climatic, geological, topographical and agricultural characteristics. For the scope of our analysis, the ADs are considered autonomous agents in the multi-attribute RPM. Most relevant crops in the area are wheat and corn. Other important crops include other cereals, fruit trees and vineyards (ER Statistica 2014).

The Po River Basin has been frequently affected by drought events since the turn of the century. Droughts occurred in 2003, 2006, 2007 and 2015, and a

\footnotetext{
${ }^{2}$ Because of the sensitive nature of the information supplied by the hydrological model used in the LPRB, its methods and some of the model outcomes are not publicly available, and could not be used in this research.

${ }^{3}$ The administrative division into regions and provinces in Italy corresponds to the second and third level of the Nomenclature des Unités Territoriales Statistiques (NUTS), or nomenclature of territorial units for statistics. NUTS classification is a hierarchical system for statistical subdivision of the EU (Eurostat 2016).
} 


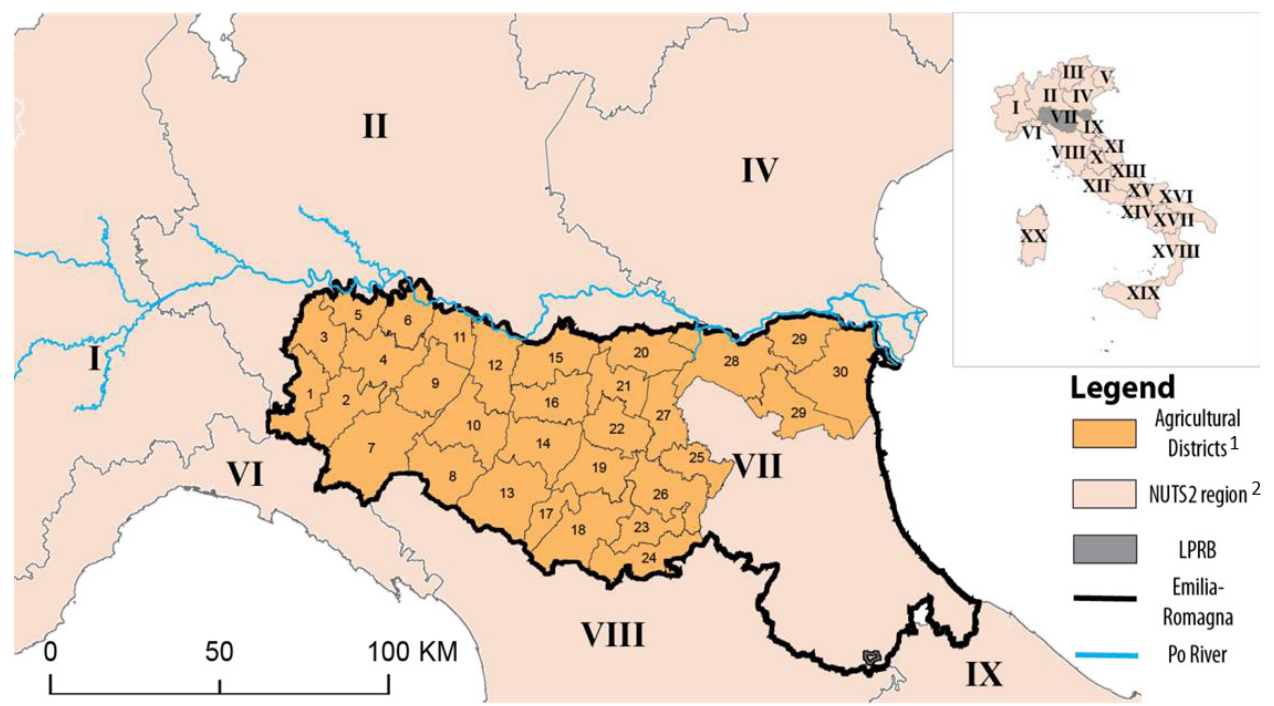

Figure 2. The Lower Po River Basin

${ }^{1}$ 1. Montagna del Medio Trebbia ; 2 . Alto Nure ; 3 . Colline del Trebbia e del Tidone ; 4. Colline del Nure e dell'Arda ; 5. Pianura di Piacenza ; 6. Basso Arda ; 7. Alto Taro ; 8. Alto Parma ; 9. Colline di Salsomaggiore ; 10. Medio Parma ; 11. Pianura di Busseto ; 12. Pianura di Parma ; 13. Montagna tra l'Alto Enza e Alto Dolo ; 14. Colline tra Enza e Secchia ; 15. Bassa Reggiana ; 16. Pianura di Reggio Emilia ; 17. Valli del Dragone e del Rossenna ; 18. Alto Panaro ; 19. Colline Modenesi ; 20. Bassa Modenese ; 21. Pianura di Carpi ; 22. Pianura di Modena ; 23. Montagna del Medio Reno ; 24 . Alto Reno ; 25. Colline di Bologna ; 26. Colline del Reno ; 27. Pianura a sinistra del Reno ; 28. Pianura di Ferrara ; 29. Bonifica Ferrarese Occidentale ; 30. Bonifica Ferrarese Orientale.

${ }^{2}$ I. Piedmont; II. Lombardy; III. Trentino-Alto Adige; IV. Veneto; V. Friuli-Venezia Giulia; VI. Liguria; VII. Emilia-Romagna (LPRB); VIII. Tuscany; IX. Emilia Romagna (other area); X. Umbria; XI. Marche; XII. Lazio; XIII. Abruzzo; XIV. Campania; XV. Molise; XVI. Apulia; XVII. Basilicata; XVIII. Regio Calabria; XIX. Sicily; XX. Sardinia.

nationwide state of emergency (SoE) was declared in 2003, 2006 and 2007 for a total duration of 20 months (PRBDA 2015). Economic consequences of droughts were heavily felt in the irrigated areas of the LPRB. Environmental uses in the LPRB, and in the Po Delta in particular, were affected by sharply decreased discharges and saline intrusion that affected drinking water supplies (Mysiak et al. 2014). Climate and hydrological models indicate that such events may occur more often in the future as a result of climate change. The spring peak of annual water discharge is projected to shift from May to April, which, combined with reduced precipitation and discharge in spring and summer, will extend and intensify the hydrological dry season and increase water stress over the basin (up to $+25 \%$ in this century according to estimations) (Coppola et al. 2014; Medri et al. 2013; Vezzoli et al. 2015). 
Despite the medium to long term planning instruments provided for by Italian legislation, ${ }^{4}$ drought management in the basin relies on reactive measures enacted during drought episodes (Calliari 2011). Traditionally, drought response has followed a command-and-control approach in which the Civil Protection Department (CPD, in Italian: Dipartimento Protezione Civile) adopts specific water restrictions for each use, with sanctions imposed for non-compliance (GU 1994). The 2003 drought event opened the way for establishing a coordinated approach, in which water restrictions are defined through consensual participatory processes in the context of a Drought Steering Committee (DSC, in Italian: Cabina di Regia). Promoted by the Po RBA, the DSC engages regional administrations; several Land Reclamation and Irrigation Boards; public entities supervising the operation of the great regulated lakes; the Italian Grid Distribution Operator; and major power producing companies located in the basin. The DSC builds upon the voluntary engagement of the main interested sectors, aiming to coordinate with one another so as to delay or prevent critical water shortages.

During the 2003 drought event, one of the most intense of the past 30 years, the DSC conducted negotiations that led to a $25-50 \%$ reduction in irrigation allotments and increased water releases from alpine reservoirs and large regulated lakes (PRBA 2003). Although insufficient to restore the balance in the basin, the decision led to a progressive increase in water flows in the Po River. Given the positive experience, the DSC was instituted as a permanent coordination mechanism for monitoring and managing water crises (PRBA 2005).

\section{Revealed Preference Model}

\subsection{Decision-making problem}

Agents aim to maximize utility, which in turn derives from the provision of valuable attributes. One such attribute is profit, but there can be others, e.g., avoidance of risk or management complexities. The question of which attributes are valuable, and to what extent, is conditioned by agents' preferences - a summary of psychological assessments determined by their beliefs (Läpple and Kelley 2013). The theory of revealed preferences shows that it is possible to elicit agents' preferences by paying attention to observed decisions and realized outcomes (in particular, the observed provision of attributes). In the case of irrigation, the range of farmers' choices includes selection of crops and their rotation, water

\footnotetext{
${ }^{4}$ These include for instance the Water Protection Plans mandated by Legislative Decree 152/99 and the Programs of Local Action to fight Drought and Desertification (PAL, in Italian: Piano di Azione Locale) envisaged by the Inter-ministerial Committee for Economic Planning's (in Italian: Comitato interministeriale per la programmazione economica) resolution 229/99.
} 
application and capital stock. This complex decision process can be simplified by representing each possible combination of crops and management techniques (involving timing, water application and capital) for which information is available (a finite set) as a separate crop with unique characteristics. Thus, the optimization problem is reduced to a decision on the crop mix within a domain (GutiérrezMartín and Gómez 2011):

$$
\begin{gathered}
\underset{x}{\operatorname{Max} U(x)=} U\left(z_{1}(x) ; z_{2}(x) ; z_{3}(x) \ldots z_{m}(x)\right) \\
\text { s.t. }: 0 \leq x_{i} \leq 1 \\
\sum_{i=1}^{n} x_{i}=1, \\
x \in F(x) \\
z=z(x) \in R^{m} .
\end{gathered}
$$

Agents decide on the crop mix $x \in R^{n}$, where $x$ is a vector containing the share of the surface area devoted to each crop $x_{i}(i=1, \ldots, n)$. Every crop $i$ has a unique combination of attributes $z(x)$ attached. All attributes are normalized dividing by the maximum feasible value, resulting in quantities of dimension one. Increasing the provision of one attribute, all things being equal, has a positive impact on farmers' utility ("more is better"). This means that the rationale of agents' choices, rather than lying in crop decisions themselves, lies in the set of utility-relevant attributes considered. Agents balance the crop mix so as to maximize the utility derived from the provision of attributes subject to a series of agronomic, policy, information and physical constraints that form the domain $F(x)$. Important elements of the domain include the irrigable and agricultural area, which constrain land use, and crop rotation, climatic conditions, know-how, water availability and Common Agricultural Policy rules, which constrain land use change. The model can be used to simulate the impact of structural policies that may lead to (dis) investments, for example through annual and perennial tradeoffs or irrigation modernization (see e.g., Gutiérrez-Martín and Gómez 2011); yet, such (dis) investments are restricted in this exercise, given the short-term focus of irrigation restrictions in the case study area.

Physical constraints include the water resources constraint, which can be expressed as:

$$
\sum_{i=1}^{n} w_{i} x_{i} \text { ha } \leq W_{g},
$$


where $W_{g}$ is the water allotted to the agent in a given scenario $g$, ha is the land allotment and $w_{i}$ are the water withdrawals necessary to irrigate crop $x_{i}$.

The multi-attribute utility function in Eq. (1) is calibrated by using revealed preference techniques. The RPM follows a positive approach, meaning that the solution to the above problem is the observed crop mix actually chosen by the farmer, denoted by $x^{\circ}$. The RPM aims to elicit a utility function that is consistent with the observed crop mix and the choice domain.

\subsection{Calibration}

By using standard microeconomic theory, the objective function parameters can be elicited for every possible combination of attributes within a finite set equalizing the Marginal Rate of Transformation $\left(\mathrm{MRT}_{k p}\right)$, i.e., the opportunity cost of trading off one unit of attribute $z_{k}$ for one unit of attribute $z_{p}$ (the slope of the efficient frontier), and the Marginal Rate of Substitution $\left(\mathrm{MRS}_{k p}\right)$, i.e., the willingness to give up one unit of attribute $z_{k}$ in exchange for a unit of attribute $z_{p}$ (the slope of the indifference curve of the utility function).

$$
\mathrm{MRT}_{k p}=\mathrm{MRS}_{k p}=-\frac{\partial U / \partial z_{p}}{\partial U / z_{k}} ; \quad p, k \in(1, \ldots, m) ; p \neq k .
$$

The multi-attribute utility function is calibrated in two steps. In the first step, a method to reveal the efficient frontier for each pair of attributes by using numerical methods is presented, and the $\mathrm{MRT}_{k p}$ estimated. In the second step, the parameters of the utility function for every possible combination of attributes within the chosen (and finite) set of attributes are elicited by equalizing the $\mathrm{MRT}_{k p}$ and $\mathrm{MRS}_{k p}$. The relevant attributes are those that minimize the distance between observed and simulated decisions.

\subsubsection{Efficient frontier and tangency point}

In order to calibrate the objective function, the efficient frontier needs to be defined. The efficient frontier represents the maximum level of attributes that agents can attain within the space of feasible decisions $F(x)$. The efficient frontier cannot be defined with a closed function, and is obtained instead through numerical methods using an optimization procedure. For a finite number of values $c=$ $(0, \ldots, 1)$ of a given attribute $z_{k}(x)$, this procedure finds the set of feasible crop decisions that maximize the value of attribute $z_{p}(x)(p \neq k)$.

$$
\begin{gathered}
\operatorname{Max}_{x}(x) \\
\text { s.t. }: z_{k}(x)=c \quad \forall k \neq p \quad c=(0, \ldots, 1)
\end{gathered}
$$


C. D. Pérez-Blanco et al.

$$
\begin{gathered}
0 \leq x_{i} \leq 1, \\
\sum_{i=1}^{n} x_{i}=1, \\
x \in F(x) .
\end{gathered}
$$

The result is an efficient frontier in the two-dimensional space defined by $\tau_{z_{p}}, z_{k}\left(X^{f}\right)$, where $X^{f}$ is the set of crop portfolios located along the frontier for attributes $z_{p} z_{k}$. The efficient frontier has to be convex - otherwise one of the attributes has no opportunity cost in terms of the other, which means that it is not utility-relevant and can be therefore excluded. In practice, this means that an increase in, say, expected income must come along with a reduction in, say, income security (Just 1975). The slope of the efficient frontier or $\mathrm{MRT}_{\mathrm{kp}}$ offers the information necessary to obtain the tangency point for the calibration of the utility function.

There are several methods that can be used to find tangency points along the frontier (Gómez-Limón et al. 2016; Gutiérrez-Martín and Gómez 2011). In this paper, we use a projection method (Gutiérrez-Martín et al. 2014; Gutiérrez-Martín and Gómez 2011), in which the optimization problem in Eqs. (8)-(12) is solved for the observed values of $z_{k}(x)$, i.e., $z_{k}(x)=c=z_{k}^{\circ}(x)$. Projecting the observed crop portfolio $\tau_{z p}, z_{k}\left(x^{\circ}\right)$ to the efficient frontier yields two points, namely $\tau_{z p}, z_{k}^{\circ}\left(x^{f}\right)$ and $\tau_{z p}^{\circ}, z_{k}\left(x^{f}\right)$. The slope between the two projected points approximates the $\mathrm{MRT}_{\mathrm{kp}}$ and is used as the tangency point for the calibration of the utility function in the next subsection. (Fig. 3).

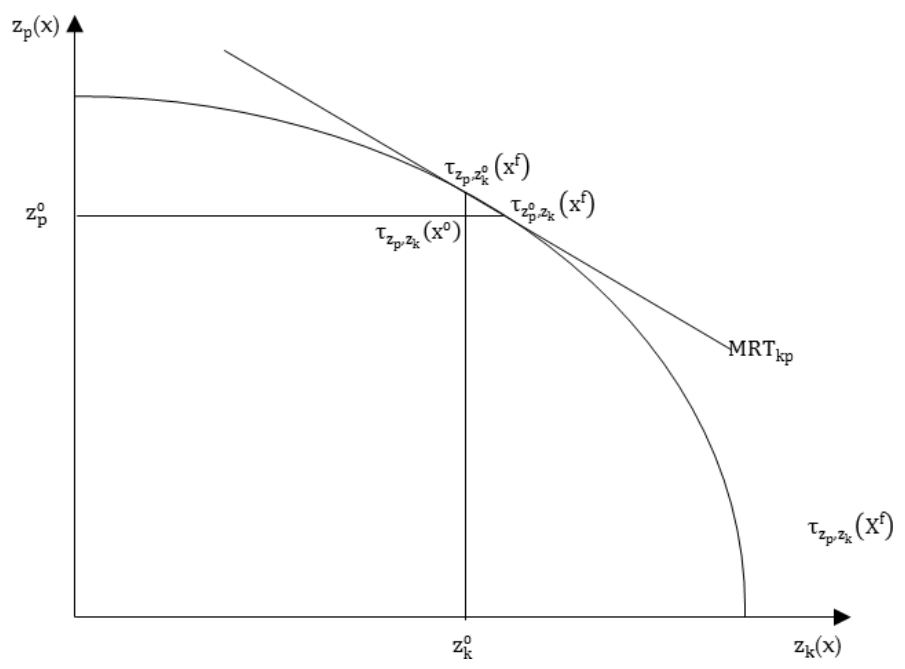

Figure 3. Efficient Frontier and Tangency Point 
Provided that agents are rational individuals who aim at maximizing their utility within the domain, and by means of a positive approach that equalizes the optimal and observed decisions, the observed crop mix $\tau_{z p}, z_{k}\left(x^{\circ}\right)$ and the frontier must be close, and so must the projected points $\tau_{z p}, z_{k}^{\circ}\left(x^{f}\right)$ and $\tau_{z p}^{\circ}, z_{k}\left(x^{f}\right)$. The projection method reduces the approximation error as compared to other alternatives (André et al. 2010; André and Riesgo 2007), but still yields an error that is measured by using calibration residuals (see next section).

\subsubsection{Utility function specification and parameters}

A Cobb-Douglas specification was chosen for the utility function. Unlike alternative additive or multiplicative-additive specifications, Cobb-Douglas specifications have a decreasing marginal utility for each attribute and yield a global optimum (Inada 1963). The Cobb-Douglas parameters are estimated as follows:

$$
\begin{gathered}
-\frac{\partial U / \partial z_{p}}{\partial U / z_{k}}=-\frac{\alpha_{p}}{\alpha_{k}} \frac{z_{k}}{z_{p}}=\mathrm{MRT}_{\mathrm{kp}}, \\
\sum_{p=1}^{m} \alpha_{p}=1
\end{gathered}
$$

this system is resolved for every possible combination within the finite set of attributes, and thus the parameters of the related utility functions are elicited. The calibrated utility functions that result are used to obtain their corresponding optimum crop portfolio $\left(x^{*}\right)$ and attributes $\left(z_{p}^{*} ; p=1, \ldots, m\right)$.

The positive approach used in RPM implies that the relevant attributes are those that more accurately resemble the observed behavior of the agent. Accuracy is assessed through calibration residuals that measure the distance between the value of observed and calibrated variables. The first calibration residual measures the distance between the observed and optimum (calibrated) crop mix:

$$
e_{x}=\sqrt{\frac{1}{n} \sum_{i=1}^{n}\left(\frac{x_{i}^{\circ}-x_{i}^{*}}{x_{i}^{\circ}}\right)^{2}} .
$$

The second calibration residual measures the distance between the observed and optimum (calibrated) attributes:

$$
e_{\tau}=\sqrt{\frac{1}{m} \sum_{p=1}^{m}\left(\frac{z_{p}^{\circ}-z_{p}^{* 0}}{z}\right)^{2}} .
$$


The ordinary arithmetic mean of the two metrics above is the average calibration residual:

$$
e=\frac{e_{x}+e_{\tau}}{2}
$$

The combination of attributes that minimizes this error is the relevant one, and its corresponding utility function is used in the simulation runs.

\subsection{Empirical model and data}

Based on a literature review of multi-attribute utility functions (Bergevoet et al. 2004; Binswanger 1982; Chung and Lee 2009; Delforce and Hardaker 1985; Gómez-Limón and Riesgo 2004; Hazell and Scandizzo 1977a,b; Just 1975; Läpple and Kelley 2013; Lynne 1995; Poppenborg and Koellner 2013; Rausser and Yassour 1981; Rodrigues et al. 2013), five attributes are explored. The first attribute considered is profit, the sole variable explaining the agent's behavior and response in single-attribute models, which is captured through expected income. Using the first moment of income distribution, we capture the inability of the agent to anticipate with certainty realized yields or prices. Profit $\left(z_{1}\right)$ is obtained in this application of the model as a function of the per hectare gross margin $\pi_{i}$ :

$$
z_{1}(x)=\sum_{i} x_{i} \pi_{i}
$$

The crop mix decision is comparable to choosing a portfolio of financial assets, in which the agent must balance assets with low expected return and risk (say treasury bonds or subsidized crops) and those with high expected return and volatility (say stock shares or vegetables). The portfolio composition will ultimately depend on the agent's attitude toward risk. The utility-relevance of risk attitudes has been repeatedly reported in the literature and is represented in this application of the model through avoided risk $\left(z_{2}\right)$ :

$$
z_{2}(x)=x^{\tau} \operatorname{VCV}(\pi(x)) x-\bar{x}^{\tau} \operatorname{VCV}(\pi(\bar{x})) \bar{x},
$$

where $\operatorname{VCV}(\pi(x))$ is the variance and covariance matrix of $z_{1}(x)$ and $\operatorname{VCV}(\pi(\bar{x}))$ is the variance and covariance matrix of $z_{1}(\bar{x})$.

However, it is possible that risk aversion and profit maximization alone are insufficient to explain the observed agent's behavior, resulting in a significant gap between the observed crop mix and the frontier. In this case, additional attributes are necessary in order to achieve a satisfactory explanation of the agent's behavior and accurately predict his responses. The problem at this stage resides in the qualitative nature of many of these attributes, which may complicate their 
measurement and demand the use of proxy variables. This is so regarding avoidance of management complexities, or management easiness, which is often cited in the literature as the third most relevant attribute explaining the agent's behavior. In this application of the model, three attributes capturing management complexity aversion, or management easiness, are considered, namely: total labor avoidance, hired labor avoidance and direct cost avoidance. There is no risk of correlation among attributes, since the outcome of the utility function is an ordinal value (Edgeworth 1881). This means that the model is not concerned about total utility or levels of utility, but rather about ranking alternative decisions coherent with observed choices:

- Total labor avoidance $\left(z_{3}\right)$ :

$$
z_{3}(x)=N(\bar{x})-N(x),
$$

where $N(x)=\sum_{i} x_{i} N_{i}$ are the total labor requirements for producing the crop mix $x, N(\bar{x})=\sum_{i} \bar{x}_{i} N_{i}$ are the total labor requirements for producing the crop mix $\bar{x}$, and $N_{i}$ is the total labor per hectare (daily wages) of crop $i$.

- Hired labor avoidance $\left(z_{4}\right)$ :

$$
z_{4}(x)=H(\bar{x})-H(x),
$$

where $H(x)=\sum_{i} x_{i} H_{i}$ are the hired labor requirements for producing the crop portfolio $x, H(\bar{x})=\sum_{i} \bar{x}_{i} H_{i}$ are the hired labor requirements used for producing the profit maximizing crop $\operatorname{mix} \bar{x}$, and $H_{i}$ is the hired labor per hectare (daily wages) of crop $i$.

- Direct cost avoidance per unit of revenue $\left(z_{5}\right)$ :

$$
z_{5}(x)=D(x)-D(\bar{x}),
$$

where $D(x)=\sum_{i} x_{i} D_{i}$ are the direct costs per unit of revenue incurred in the production of the crop mix $x, D(\bar{x})=\sum_{i} \bar{x}_{i} D_{i}$ are the direct costs per unit of revenue incurred in the production of the profit maximizing crop mix $\bar{x}$, and $D_{i}$ are the direct costs per hectare of crop $i$.

The model is flexible and could be used to explore additional attributes by using the same calibration method explained above. For example, it could be informative to explore the role of climate, weather and market forecasts on agents' behavior. This is nonetheless limited by the availability of data, which ultimately constrained the use of these attributes in our case study area. It is worth noting that the inclusion of additional variables does not guarantee a more accurate calibration and results. Only if attributes are relevant in explaining agents' decisions could errors be reduced and accuracy improved. 
The model is calibrated by using data from ER Statistica (2016) (land use and yields), ISMEA (2016) (market prices), INEA, 2016 (family and hired labor, other costs, subsidies and other revenues), ISTAT 2013 (water use and irrigation efficiency). Data are available for 55 crops and $70.4 \%$ of the case study area during the period 1996-2011. Prices base year is 2000, as in the MRIA model, and the calibration year (observed crop portfolio) is 2014 .

\subsection{Simulation of irrigation restrictions}

Once the multi-attribute utility function is calibrated, Eqs. (1)-(6) can be used to assess agents' responses to a specific water policy or shock. In this particular exercise, a series of simulations is run in which water withdrawals $W_{g}$ in Eq. (6) are reduced by $0-50 \%$ at $1 \%$ intervals $(g=0, \ldots, 50)$. For every simulation scenario, agents reassess their decisions and find the optimal crop mix $\left(x^{*}\right)$ and its corresponding attributes $\left(z_{p}^{*} ; r=1, \ldots, m\right)$. This information can be used to estimate the Gross Value Added (GVA) of the agricultural sector in the $\operatorname{LPRB}\left(Y_{g}^{\mathrm{RPM}}\right)$, a function of available water:

$$
Y_{g}^{\mathrm{RPM}}=f\left(W_{g}\right) .
$$

The simulation takes place at the beginning of the irrigation season, when farmers can adjust their crop portfolio. Admittedly, this is not always the case restrictions could appear, or be further strengthened, when crop decisions have already been made. This uncertainty is known by agents, who base their crop mix choice on the expected income and its variability, which are also conditioned by past droughts. This also means that the output of the simulation shows expected values that may not correspond to the realized impacts of the drought, which may be higher (if drought conditions worsen) or lower (if drought conditions improve).

The output in Eq. (23) is transformed to produce the inputs for the macroeconomic simulation. For each simulation run $g$, a productivity shock $\sigma_{g}$ is obtained as a function of the ratio between the estimated GVA and the GVA in the baseline $(g=0)$ :

$$
\sigma_{g}=\gamma \frac{Y_{g}^{\mathrm{RPM}}}{Y_{0}^{\mathrm{RPM}}},
$$

where $\gamma$ is a fixed coefficient capturing the share of agricultural GVA that the case study area (LPRB) represents in its corresponding region (Emilia Romagna Region).

The productivity shock offers aggregated information at a NUTS2 level and can be used as an input to conduct simulations in regionally calibrated macroeconomic models such as the MRIA model (Koks et al. 2015). 


\section{The MultiRegional Impact Assessment Model}

\subsection{Model basics}

The MRIA model is employed to calculate the regional impacts in both the affected and surrounding regions. The model was originally developed for the entire European Union, consisting of 256 NUTS 2 regions, 59 products and 14 sectors (Koks and Thissen 2016), following the European Classification of Products by Activity (Nace 1.1 - CPA 2002). For the purpose of this paper, only the 20 Italian regions are considered, and the rest of Europe is aggregated into a single unit. More specifically, all imports from all other EU regions are aggregated in one row and all exports to other EU regions are aggregated in one column.

This model allows for an endogenously determined new post-disaster optimum with shifts between main suppliers within the boundaries of the existing (trade and) production structure of the (regional) economy. The objective function of the model, Eq. (25), minimizes total production over all regions. More specifically, each industry in each region aims to minimize its costs under a Walras-Leontief production function, per input, per industry and per region, given the demand for products and the available technologies to produce the products. These technologies describe how industries can make a mix of products out of a specific set of inputs (the Leontief production function). Technologies are "owned" by the different industries in the different regions and are therefore available only to them. The mix of inputs that each industry requires to make its specific mix of products represents its production technology and is described by the use table (which describes how many inputs an industry uses to create products). The mix of products that each industry can make by using this technology is described in the supply table (see Appendix 2 for an illustration of the type of multiregional supply-use table used in this study). The complete MRIA Model can be described by the following set of equations, with $t=$ time, with $l=1, \ldots, L$, with $L=$ number of products, with $g$ and $h=1, \ldots, I$, with $I=$ number of industries, $r=1, \ldots, N$ and with $s=1, \ldots, N$, with $N=$ number of NUTS2 regions. Appendix A includes a full list of all variables and their description.

$$
\begin{gathered}
\text { Min } z_{t}=\sum_{g, r} q_{g, r, t}, \\
\text { s.t. }: s_{r, t} \geq\left(I-\widehat{\eta}_{r}\right)\left(u_{r, t}+f_{r, t}+\nu_{r, t}\right)-\varpi_{r, t}+e_{r, t}^{\mathrm{EU}}+e_{r, t}^{\mathrm{world}}, \\
\varpi_{r, t}=\operatorname{Max}\left[0,\left(I-\widehat{\eta}_{r}\right)\left(u_{r, t}+f_{r, t}+\nu_{r, t}\right)+e_{r, t}^{\mathrm{EU}}+e_{r, t}^{\mathrm{world}}-\delta s_{r, t}^{\mathrm{max}}\right], \\
e_{r, t}^{\mathrm{EU}}=\sum_{s} T_{s} \mu_{s}\left(u_{s, t}+f_{s, t}+\nu_{s, t}\right)+\sum_{s} T_{s} \mu_{s} \varpi_{s, t},
\end{gathered}
$$


where:

$$
\begin{gathered}
q_{g, r, t} \geq 0, q_{g, r, t} \leq q_{g, r, t}^{\max }, \varpi_{g, r, t} \geq 0, \nu_{g, r, t} \geq 0, \\
s_{r, t}=C_{r} q_{r, t}, s_{r, t}^{\max }=C_{r} q_{r, t}, \\
u_{r, t}=B_{r} q_{r, t}, \\
\eta_{r}=\left(\widehat{m}_{r}^{\mathrm{EU}}+\widehat{m}_{r}^{\text {world }}\right)\left(u_{r}^{\text {base }}+f_{r}^{\text {base }}\right)^{-1} \\
\mu_{r}=\left(\widehat{m}_{r}^{\mathrm{EU}}\right)\left(u_{r}^{\text {base }}+f_{r}^{\text {base }}\right)^{-1} .
\end{gathered}
$$

The MRIA model assumes, in line with standard IO modeling, a demand-determined economy. More specifically, demand from all Italian regions and the rest of the world has to be satisfied by the total supply in all regions and the rest of the world. This implies that if there is a supply restriction in a region (i.e., reduced production as a result of a drought), the model aims to substitute to a non-affected supplier to satisfy demand. The supply of products in all regions should be equal to or larger than the demand for these products from all regions [Eq. (26)]. The possibility of supply being larger than demand is an essential element in the model, which allows for modeling inefficiencies in the economy due to limits in the production capacity in the disaster affected area. The production in all regions will take place at the lowest possible costs (industries minimize costs), given demand, the available technologies and the maximum capacity of industries. The vector $\varpi_{r, t}$ defines the required additional imports of the affected regions from other regions to satisfy the demand for products which cannot be satisfied because of lost production capacity in their own regions [Eq. (27)]. The last term in Eq. (27) consists of the maximum capacity of a region to produce goods, given the available production technologies. Factor $\delta$ describes to what extent the regions will exhaust all of their technology to produce a product in demand before it starts to import additional products. If $\delta$ equals one, the region will only start importing a product when all possible technologies have been used, with very large inefficiencies as a consequence. Finally, Eq. (28) closes the model by ensuring that additional imports due to limits in regional production capacity or increased production are produced by the exporting regions.

\subsection{Simulation of irrigation restrictions}

A specific event that represents an economic disruption is modeled by reducing the maximum capacity of the affected sector(s). In the case of a drought, the maximum capacity of the agricultural sector is reduced and will become binding for the affected sector in the affected region. This is shown in Eq. (4), where $\mathbf{y}$ is Value 
Added and $\boldsymbol{\sigma}$ the productivity shock as a result of the drought in the agricultural sector.

$$
y_{r, t}^{\max }=y_{r, t}\left(I-\widehat{\sigma}_{r, t}\right) .
$$

In the MRIA model, there are two ways in which the supply for products can be increased to satisfy the remaining demand. First, the model aims to increase the production in sectors in the affected region that are not at their maximum capacity but can produce the product in demand as a by-product. For the agricultural sector, this effect is, however, limited. An agricultural product is often the core activity of a company, and never the by-product of another production process. However, if a different sector is able to take over some of the production, inefficiencies in the economy will occur as these products are no longer made by the best possible technology (i.e., we assume that the sector that originally produces the product produces the most efficient one of its kind). Second, imports to the region with an excess demand can be increased. The option to increase imports of a certain product is only used when the combined maximum capacity of the total of all sectors that can produce this product is unable to satisfy the demand. These inefficiencies make the model different from IO and CGE models that impose equality between demand and supply and therefore do not deal with these types of inefficiencies. In the MRIA model, these inefficiencies result in unnecessary byproducts not in demand that are supplied to the market. The latter should therefore be interpreted as additional costs for the producer. It should be noted that these inefficiencies occur at the regional level and not at the industry level; they are caused by the limited available technologies and associated machinery, given the demand for products in a region after a disaster.

The distribution of imports from other regions is determined by a fixed proportion, which is in line with standard multiregional IO models (see e.g., Miller and Blair 2009). It should be noted that large disasters may result in large additional imports which may cause exporting regions, not directly hit by the disaster, to reach the maximum capacity for certain industries. This is endogenously determined in the model.

\subsection{Data}

The MRIA model uses a regionalized version for Italy of the European multiregional supply and use table, developed by PBL Netherlands Environmental Assessment Agency (Thissen et al. 2014). The multiregional supply and use tables are built around 59 product categories which cover both goods and services following the European Classification of Products by Activity (Nace 1.1 - CPA 2002). 
The data sources used to construct the dataset are (1) the national accounts of 25 EU countries, (2) international trade data on goods from Feenstra et al. (2005) and services from Eurostat (2009a,b), (3) regional information on production, investment and consumption made available via Cambridge Econometrics (2008), (4) information on freight transport among European regions from the Dutch Ministry of Infrastructure and the Environment (2007) and (5) first and business class airline ticket information from SEO (2010).

\section{Results}

\subsection{Calibration}

Table 1 presents the calibration results (i.e., the value of the Cobb-Douglas utility function parameters or $\alpha_{p}$ ) and the corresponding calibration residuals for the ADs of the LPRB, by using the RPM and the multi-attribute utility function. Of the five attributes explored (see Sec. 3.3), only three are found relevant in explaining farmers' decisions, namely profit $\left(z_{1}\right.$, corresponding parameter: $\left.\alpha_{1}\right)$, risk avoidance $\left(z_{2}\right.$, corresponding parameter: $\left.\alpha_{2}\right)$ and total labor avoidance $\left(z_{3}\right.$, corresponding parameter: $\alpha_{3}$ ). Profit and risk avoidance are relevant in all 30 ADs, while total labor avoidance is relevant in explaining the behavior of 18 ADs. Variability in the values of the parameters reflects the heterogeneity of the LPRB. For example, a representative farmer of Colline di Bolgona is close to profit maximizing $\left(\alpha_{1}=0.989\right)$, with risk avoidance $\left(\alpha_{2}=0.011\right)$ having a minor yet significant role in explaining his/her behavior. On the other hand, the behavior of a representative farmer of Pianura di Reggio Emilia is largely explained by his/her avoidance of management complexities $\left(\alpha_{3}=0.254\right)$, which typically relates to ADs with a traditional agricultural structure (large shares of corn and wheat in the case of the Emilia Romagna area). Larger risk aversion coefficients such as those observed in Alto Reno $\left(\alpha_{2}=0.165\right)$ and Pianura di Modena $\left(\alpha_{3}=0.155\right)$ show a higher willingness to sacrifice the provision of other attributes if this contributes to limiting risk. If agents shared the same domain (set of restrictions), ADs with a higher $\alpha_{1}, \alpha_{2}$ and $\alpha_{3}$ would display crop portfolios with a higher profit, risk avoidance and management complexities than others, respectively.

Average calibration residuals display satisfactory metrics for performance evaluation below 10\% (Pérez-Blanco et al. 2016).

\subsection{Simulation}

\subsubsection{Microeconomic simulation}

The microeconomic simulation reduces irrigation withdrawals by $0-50 \%$ at $1 \%$ intervals $(g=0, \ldots, 50)$ and assesses agents' responses, resolving the optimization 
Table 1. RPM Calibration Results and Residuals

\begin{tabular}{|c|c|c|c|c|c|c|c|}
\hline \multicolumn{2}{|r|}{ Agricultural District } & \multicolumn{3}{|c|}{ Parameter } & \multicolumn{3}{|c|}{ Calibration residuals } \\
\hline Nr. & Name & $\alpha_{1}(\%)$ & $\alpha_{2}(\%)$ & $\alpha_{3}(\%)$ & $e_{\tau}(\%)$ & $\mathrm{e}_{x}(\%)$ & e (\%) \\
\hline 1 & Montagna del Medio Trebbia & 99.90 & 0.10 & 0.00 & 3.50 & 0.10 & 1.80 \\
\hline 2 & Alto Nure & 94.00 & 1.00 & 4.70 & 1.40 & 7.00 & 4.20 \\
\hline 3 & Colline del Trebbia e del Tidone & 81.30 & 4.90 & 13.80 & 4.50 & 2.00 & 3.30 \\
\hline 4 & Colline del Nure e dell'Arda & 84.50 & 3.70 & 11.70 & 4.30 & 3.90 & 4.10 \\
\hline 5 & Pianura di Piacenza & 87.50 & 1.90 & 10.60 & 0.90 & 0.00 & 0.50 \\
\hline 6 & Basso Arda & 75.10 & 0.70 & 24.20 & 1.80 & 4.70 & 3.30 \\
\hline 7 & Alto Taro & 97.60 & 2.40 & 0.00 & 0.50 & 0.10 & 0.30 \\
\hline 8 & Alto Parma & 98.80 & 0.70 & 0.50 & 0.60 & 0.10 & 0.40 \\
\hline 9 & Colline di Salsomaggiore & 75.40 & 8.70 & 15.90 & 0.30 & 0.10 & 0.20 \\
\hline 10 & Medio Parma & 98.90 & 1.10 & 0.00 & 2.90 & 4.00 & 3.50 \\
\hline 11 & Pianura di Busseto & 86.30 & 1.00 & 12.70 & 0.10 & 3.80 & 2.00 \\
\hline 12 & Pianura di Parma & 86.10 & 1.30 & 12.60 & 0.90 & 6.00 & 3.50 \\
\hline 13 & Montagna tra l’Alto Enza e Alto Dolo & 99.20 & 0.80 & 0.00 & 0.10 & 0.10 & 0.10 \\
\hline 14 & Colline tra Enza e Secchia & 99.50 & 0.50 & 0.00 & 0.20 & 0.10 & 0.20 \\
\hline 15 & Bassa Reggiana & 76.30 & 1.40 & 22.30 & 2.10 & 7.00 & 4.60 \\
\hline 16 & Pianura di Reggio Emilia & 68.30 & 6.20 & 25.40 & 2.60 & 10.40 & 6.50 \\
\hline 17 & Valli del Dragone e del Rossenna & 79.60 & 0.50 & 19.90 & 3.60 & 2.00 & 2.80 \\
\hline 18 & Alto Panaro & 86.30 & 13.70 & 0.00 & 3.30 & 9.60 & 6.50 \\
\hline 19 & Colline Modenesi & 88.90 & 11.10 & 0.00 & 3.70 & 8.30 & 6.00 \\
\hline 20 & Bassa Modenese & 80.70 & 4.80 & 14.50 & 0.50 & 2.70 & 1.60 \\
\hline 21 & Pianura di Carpi & 82.60 & 10.60 & 6.80 & 1.30 & 6.60 & 4.00 \\
\hline 22 & Pianura di Modena & 84.50 & 15.50 & 0.00 & 1.20 & 5.40 & 3.30 \\
\hline 23 & Montagna del Medio Reno & 97.20 & 2.80 & 0.00 & 3.30 & 9.00 & 6.20 \\
\hline 24 & Alto Reno & 83.50 & 16.50 & 0.00 & 2.30 & 0.10 & 1.20 \\
\hline 25 & Colline di Bologna & 98.90 & 1.10 & 0.00 & 4.20 & 9.90 & 7.10 \\
\hline 26 & Colline del Reno & 99.00 & 1.00 & 0.00 & 5.70 & 7.00 & 6.40 \\
\hline 27 & Pianura a sinistra del Reno & 80.80 & 7.10 & 12.10 & 1.10 & 7.40 & 4.30 \\
\hline 28 & Pianura di Ferrara & 80.70 & 2.80 & 16.50 & 1.30 & 1.40 & 1.40 \\
\hline 29 & Bonifica Ferrarese Occidentale & 82.90 & 9.40 & 7.70 & 2.00 & 11.40 & 6.70 \\
\hline 30 & Bonifica Ferrarese Orientale & 85.80 & 3.60 & 10.60 & 2.70 & 14.00 & 8.40 \\
\hline
\end{tabular}

problem in Eqs. (1)-(6) by using the objective functions calibrated in the previous section. In order to continue irrigating high value added crops, farmers relinquish marginal water uses, which typically correspond to crops characterized by lower gross margin, labor intensity and GVA. Figure 4 presents, for each AD in the LPRB and selected irrigation restriction scenarios, GVA losses measured as a percentage of the GVA in the baseline $(g=0)$.

Aggregate losses in the LPRB range between $-0.14 \%$ GVA (scenario $g=1$ ) and $-16.01 \%(g=50)$ of LPRB's GVA in the baseline $(g=0)$. In some ADs, losses can be as large as $-22.8 \%$ of the GVA when irrigation withdrawals are 


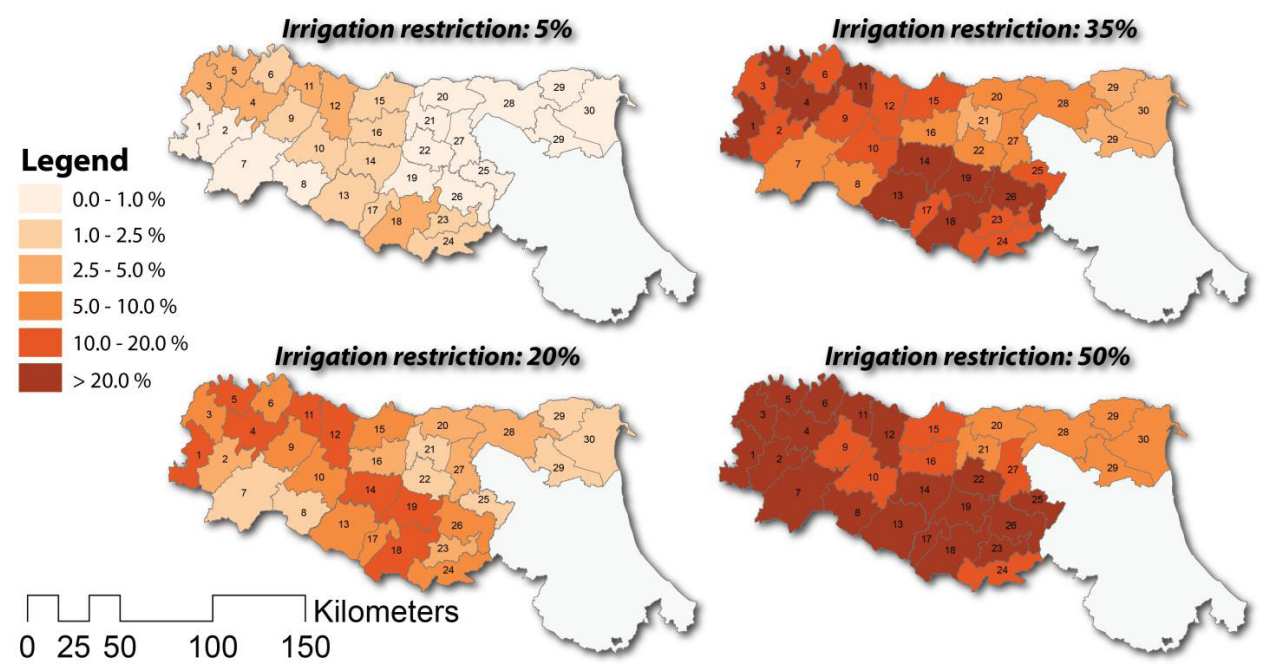

Figure 4. GVA losses (\%, 2000 prices) for Selected Irrigation Restrictions

reduced by $35 \%$, and hit $-40.3 \%$ when irrigation withdrawals are halved. The RPM provides valuable information on the magnitude and distribution of impacts below the regional level. For example, a 50\% reduction of irrigation withdrawals reduces GVA by EUR 78/ha both in the ADs of Bonifica Ferrarese Orientale and the Montagna del Medio Trebbia; nonetheless, in Bonifica Ferrarese Orientale this figure represents less than 6\% of the GVA in the baseline, and almost 33\% in the Montagna del Medio Trebbia. This is explained by the fact that Bonifica Ferrarese Orientale has a significant surface of water intensive and low value added crops (mostly rice), and farmers relinquish these marginal water uses to irrigate crops with a higher value added. In comparison, most crops available in the Montagna del Medio Trebbia have a more modest and evenly distributed value added, and there is no such pool of water resources allotted to water intensive and lower value added crops that farmers can draw upon. This divergence between absolute loss and its relative impact is observable throughout the basin: while relative GVA losses are more significant in the southern and western areas of the LPRB, absolute losses are in general larger in the profitable ADs downstream. This information can serve to balance cost-effectiveness and equity issues across ADs in the implementation of irrigation restrictions.

Irrigation restrictions in the Po River Basin District are based on a proportional rule that relinquishes a predetermined percentage of the water allotment from farmers, sometimes in disregard of the economic losses involved (Mysiak et al. 2014; PRBDA 2015). Revising this allocation rule can enhance cost-effectiveness 


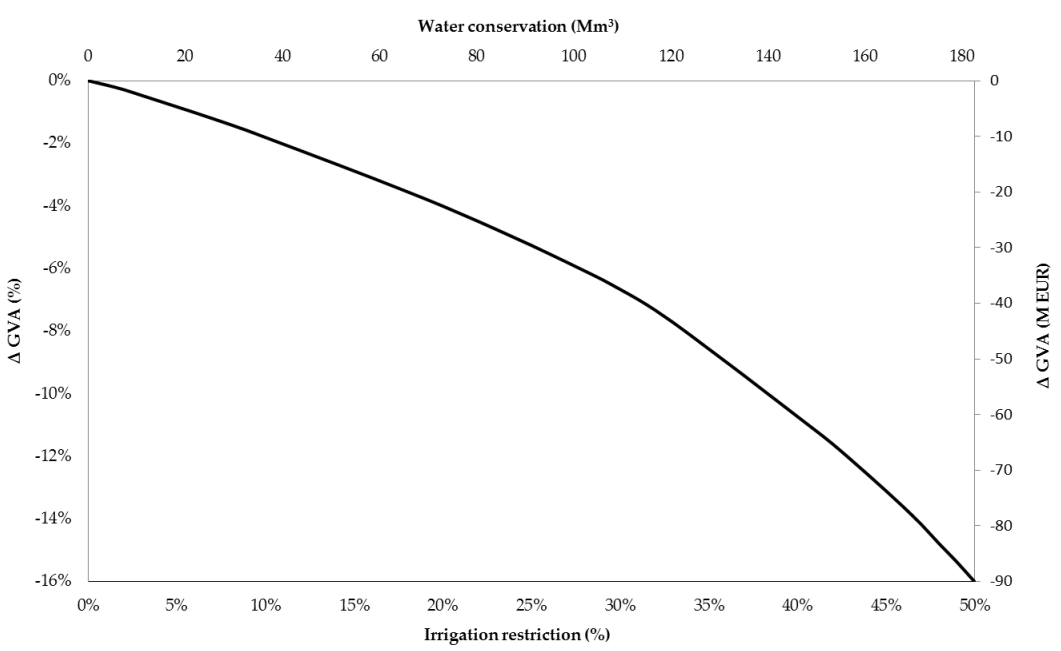

Figure 5. Tradeoffs in Irrigation Restrictions: Water Conservation versus GVA Losses (2000 Prices) in the LPRB

and equity, but it can also be contested by some parties, incur large transaction costs ${ }^{5}$ and be infeasible in the short to medium term. The macroeconomic simulation that follows aims to illustrate the economic implications of current drought management and follows a proportional rule. This information can be used as a benchmark to assess other reallocation rules that may be explored by policymakers, including possible institutional arrangements for trading water between regions, which could also be evaluated by extending the methods presented in this work. Figure 5 shows the tradeoffs between water conservation and GVA losses in the LPRB for all simulation runs, following a proportional rule for irrigation restrictions.

As the water availability constraint is strengthened, trading off GVA for water conservation becomes costlier (rising incremental losses). A hypothetical water conservation (irrigation restriction) target of $25 \mathrm{Mm}^{3}$ (6.5\%) would cost EUR 0.26/ $\mathrm{m}^{3}$; $50 \mathrm{Mm}^{3}$, EUR $0.29 / \mathrm{m}^{3} ; 100 \mathrm{Mm}^{3}$, EUR $0.33 / \mathrm{m}^{3}$; and $150 \mathrm{Mm}^{3}$, EUR $0.41 / \mathrm{m}^{3}$.

\subsubsection{Macroeconomic simulation}

GVA estimations in the microeconomic model $\left(Y_{g}^{\mathrm{RPM}}\right)$ provide the necessary information to calculate the productivity shock that feeds macroeconomic simulations $\left(\sigma_{g}\right)$. The productivity shock first reproduces the GVA losses forecast by the

\footnotetext{
${ }^{5}$ Transaction costs include the resources used to define the problems that institutions are intended to solve and to change institutions and organizations (Marshall 2013).
} 


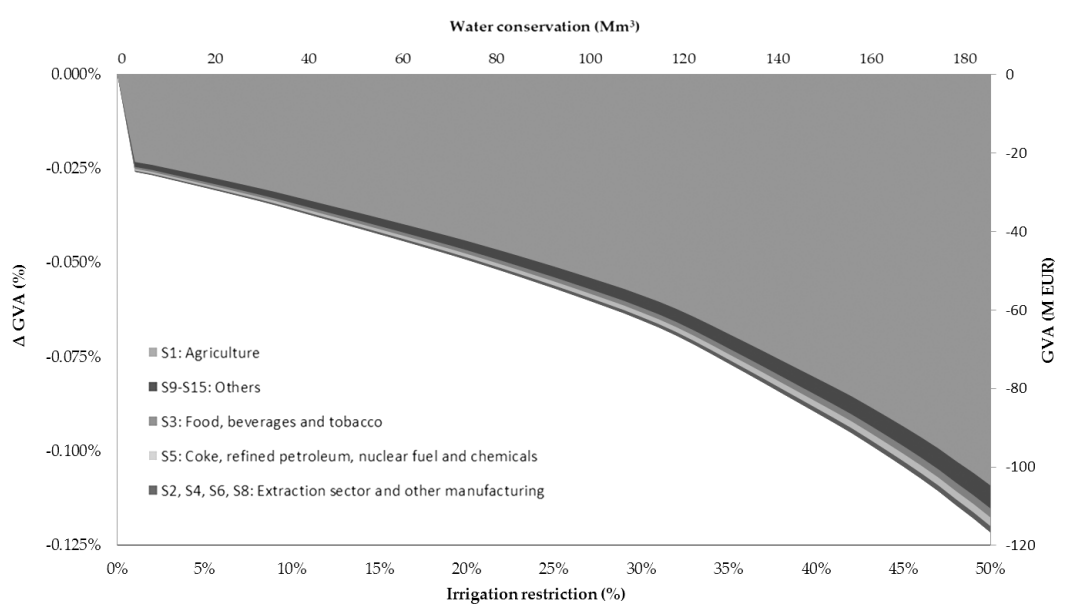

Figure 6. Tradeoffs in Irrigation Restrictions: Water Conservation versus GVA Losses (2000 Prices) in the Emilia Romagna Region

RPM, only this time in a macroeconomic context. The MRIA model then looks for a new equilibrium and estimates, for every irrigation restriction scenario, the impacts on sectorial and regional GVA. Figure 6 presents the sectorial disaggregation of the impacts of irrigation restrictions in the Emilia Romagna Region, where the LPRB is located. For the sake of simplicity, the results produced by the model for the 15 economic sectors considered are aggregated and presented in Fig. 6 for five groups, namely: S1 (agriculture); S3 (food, beverages and tobacco), S5 (coke, refined petroleum, nuclear fuel and chemicals); S2, S4, S6 and S8 (mining, quarrying and energy supply; textiles and leather; electrical and optical equipment; other manufacturing); and S9 to S15 (construction; distribution; hotels and restaurants; transport, storage and communications; financial intermediation; real estate, renting and business activities; non-Market Services). Figure 7 displays, for selected scenarios, the impact irrigation restrictions have on the GVA of the 20 Italian regions.

The Emilia Romagna Region, where the LPRB is located, is the region most affected. Negative feedbacks amplify the initial shock and inflate GVA losses as compared to the microeconomic simulation. Negative impacts are concentrated in the agricultural sector (S1), whose GVA losses range between -22 M EUR $(-0.66 \%$ agricultural GVA, scenario $g=1)$ and $-103.8 \mathrm{M}$ EUR $(-3.1 \%$, $g=50)$. The aggregation of sectorial impacts results in an overall reduction of the GVA of the Emilia Romagna Region that ranges between -24.67 M EUR $(-0.03 \%$ Emilia Romagna's GVA, $g=1)$ and -115.7 M EUR $(-0.12 \%, g=50)$. GVA losses in the agricultural sector lead to disruptions in the food industry (S3) 
Irrigation restriction: $5 \%$

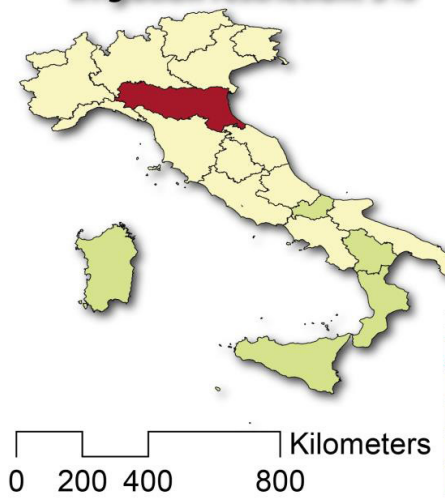

Irrigation restriction: $20 \%$

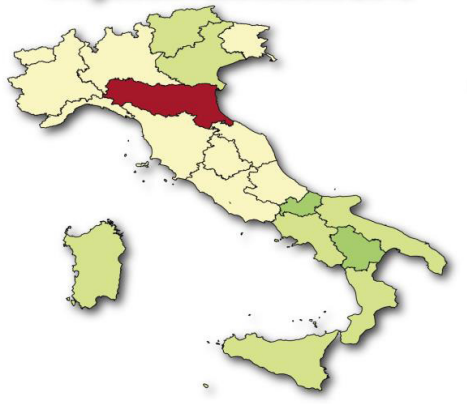

Irrigation restriction: $35 \%$

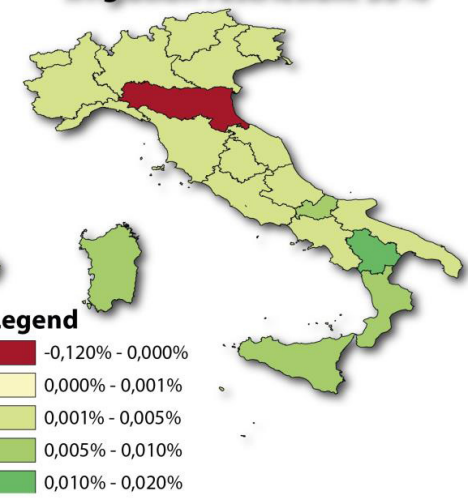

Irrigation restriction: $50 \%$

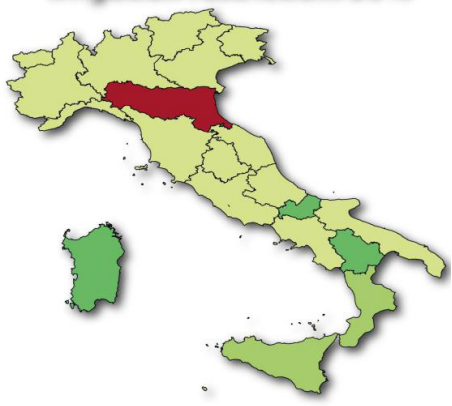

Figure 7. GVA losses (\% of GVA in the Baseline) for Selected Irrigation Restrictions in Italian Regions

through forward linkages (from $-0.48 \mathrm{M}$ EUR, or $-0.02 \%$ of sector's GVA, in $g=1$ to $-2.27 \mathrm{M}$ EUR, or $-0.1 \%$ in $g=50$ ), and in the chemical and refinery industry (S5) through backward linkages (from $-0.47 \mathrm{M}$ EUR, or $-0.03 \%$ of its GVA, in $g=1$ to $-2.2 \mathrm{M} \mathrm{EUR,} \mathrm{or}-0.07 \%$ in $g=50$ ). To a lesser extent, the remaining economic sectors are also negatively impacted, with the exception of electrical and optical equipment (S6) and Non-market services (S15), which experience marginal increases in the GVA.

The linkages that economic sectors from other Italian regions have with those in Emilia Romagna, both as customers of outputs and/or supplier of inputs, are affected by the contraction of production, which may result in production inefficiencies (see Section 4.3) that negatively affect the GVA. On the other hand, the contraction of production in the Emilia Romagna Region results in an excess of demand in the region that propels the production of substitute goods elsewhere in Italy. The latter effect prevails in the macroeconomic assessment conducted in this 
paper, which shows that irrigation restrictions in Emilia Romagna have a positive impact on the GVA of other Italian regions, mostly through the production of agricultural goods. Agricultural GVA in the rest of Italy increases between $6 \mathrm{M}$ EUR $(+0.02 \%, g=1)$ and 28.02 M EUR $(+0.11 \%, g=50)$. The regions most benefitted are Molise $(+0.001 \%$ total GVA in $g=1,+0.02 \%$ in $g=50)$, Basilicata (from $+0.001 \%$ to $+0.013 \%$ ), Sardinia (from $+0.001 \%$ to $+0.012 \%$ ), Calabria (from $+0.009 \%$ to $+0.02 \%$ ) and Sicily (from $+0.001 \%$ to $+0.008 \%$ ), because of the importance of agriculture and other affected sectors in Emilia Romagna, in their economy and the significant trade relations with this region. GVA growth nationwide compensates nearly $26.4 \%$ of GVA losses in Emilia Romagna, although the aggregation of regional impacts still results in an overall reduction of the Italian GVA that ranges between -18.08 M EUR $(-0.002 \%$ Italian GVA, $g=1)$ and -85.12 M EUR $(-0.009 \%, g=50)$. This outcome highlights the capacity of the Italian economy to absorb a significant part of the damages caused to the agricultural output of a major region, and underpins the rationale of solidarity policies in the face of natural disasters such as droughts.

When macroeconomic impacts are accounted for, trading GVA off for water conservation becomes costlier as compared to the microeconomic simulation. For example, while conserving $100 \mathrm{Mm}^{3}$ costs EUR $0.33 / \mathrm{m}^{3}$ in the microeconomic simulation, this figure rises to EUR $0.42 / \mathrm{m}^{3}$ if nationwide impacts are considered, and to EUR $0.57 / \mathrm{m}^{3}$ if only the impacts within the Emilia Romagna Region are considered.

It is worth noting that drought is a systemic risk that can affect multiple regions and basins at the same time. Basin-wide droughts demand basin-wide irrigation rationing policies, possibly leading to larger direct and indirect impacts than those estimated in this work. The regions where restrictions are applied could be expected to concentrate the losses, while regions producing products to substitute those affected by the drought would be most benefitted. This paper aims to both demonstrate and take a first step toward the development of a basin-wide model that delivers valuable insights into the economic impacts of major drought events and sensible water policies.

\subsection{Discussion}

The EU Action on Water Scarcity and Droughts has called on policy makers to develop instruments that address irrigation restrictions in a cost-effective and equitable manner, including water charges and complementary economic instruments (e.g., crop insurance) (EC 2012). Yet, actual water scarcity and drought management at a basin level involves a reactive and incremental strategy that largely focuses on new supplies and improving the efficiency of existing ones, even in 
closed basins with inelastic supply (Schmidt and Benítez-Sanz 2012). When droughts inevitably happen, command-and-control and/or DSC approaches are typically used to define planned or ad-hoc irrigation restrictions, often following a proportional rule that curtails a fixed percentage of the water allotment from farmers (Strosser et al. 2012).

The results obtained in the microeconomic simulation show that this is neither cost-effective (productive uses can be affected), nor equitable (asymmetric impacts). GVA losses at an AD level are amplified in the macroeconomic simulation through negative feedbacks among the economic sectors of the Emilia Romagna Region. This is partially but not fully compensated through GVA growth in the rest of the Italian territory. On average, the GVA losses estimated for the LPRB by using the microeconomic simulation represent 58.6\% (Emilia Romagna) and $79.7 \%$ (Italy) of the GVA losses estimated in the macroeconomic simulation (Fig. 8).

This outcome highlights the importance of the inter-sectorial linkages within and among regions. Yet, EU-wide studies analyzing the economic impact of droughts largely focus on direct losses and ignore their broad economic repercussions, both negative (negative feedbacks) and positive (substitution effect). Consequently, available estimates that place annual losses in Europe from droughts at EUR 6.2 billion are possibly biased and underestimated (Strosser et al. 2012). One may argue that available macroeconomic models can be used to correct this

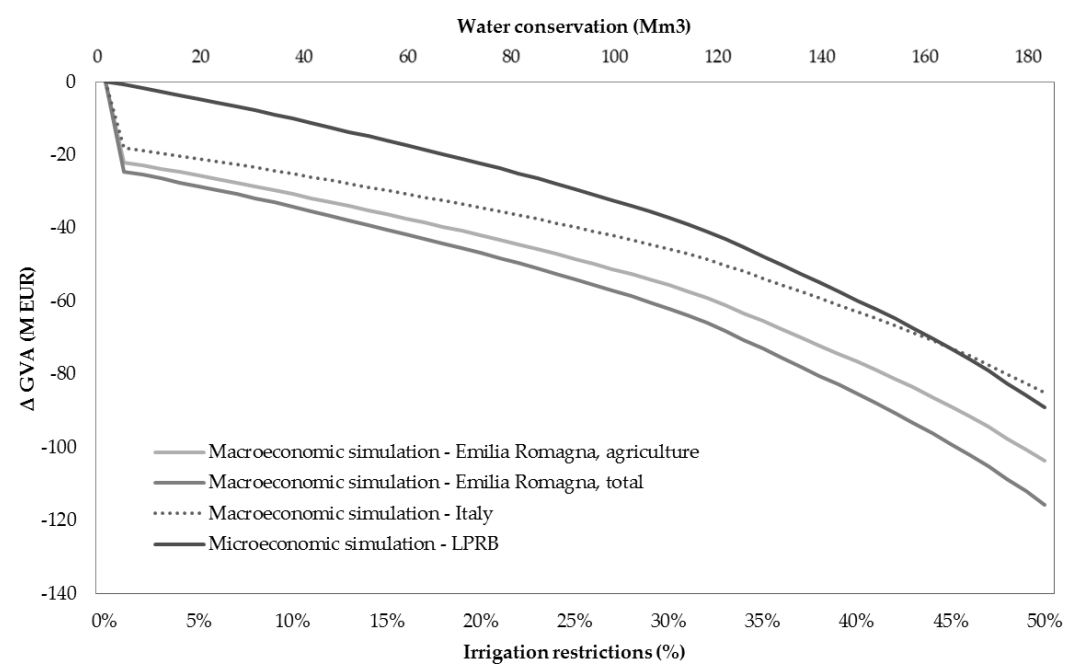

Figure 8. Tradeoffs in Irrigation Restrictions: Water Conservation versus GVA Losses (2000 Prices), Micro- and Macroeconomic Simulations 
bias. On the other hand, the heterogeneous traditions, climate, orography, soils and infrastructure of southern European regions often give rise to an intricate mosaic of crops and management practices that makes it unrealistic to consider the agricultural activity of a region as a single large agricultural entity. Furthermore, focusing on aggregate quantities macroeconomic models misses the rationale behind the behavior of farmers. Finally, the reallocation of resources in macroeconomic models is often based on competition, while in Europe and most regions worldwide water endowments are allotted according to criteria other than efficiency (e.g., historical rights, queuing), and water charges are set by the public administrations — often in a rather intricate way.

Micro- and macroeconomic assessments complement each other and offer valuable information for a better understanding of the magnitude and distribution of the economic impacts of water resources management strategies. Limiting water withdrawals in ADs with higher water productivity may have a significant impact on agricultural output and inflate the negative feedbacks on macroeconomic GVA that result from inter-sectorial linkages. On the other hand, strengthening water allocation constraints in those ADs with lower water productivity would reduce the magnitude of local as well as broad economic losses, and a fraction of the GVA losses prevented could be used to compensate those suffering restrictions. This could be addressed, for example, through incremental charges and cross-subsidization, or alternatively through trading schemes in which buyers purchase water resources to prevent the loss of high value added crops and sellers are compensated for relinquishing (part of) their water allotment. While this may reduce the abatement costs of droughts and contribute to mitigating negative distributive impacts, transaction costs could be high and complementary estimations on their impact would be necessary before deciding whether or not to advance in this or another direction.

The exercise also makes it possible to identify those negatively and positively affected by the policy. The asymmetric economic impacts on the agricultural sector in Italy are addressed through the National Solidarity Fund (legislative decree 102/2004), which provides compensatory measures to uninsurable crops in case of exceptional atmospheric conditions and natural disasters, and is fed by general taxation. Nonetheless, this mechanism offers partial compensation of losses and does not address the broad economic repercussions of drought. Some form of collaboration among regions within the same basin (in this case the PRB as a whole) could be employed ex-ante to minimize total GVA losses. Irrigation restrictions based on a basin-wide economic assessment would avoid or reduce impacts on areas with higher water productivity. Regions negatively affected by water limitations would then be compensated on the basis of the GVA losses 
prevented elsewhere. Currently, no institutional setting is in place to support this kind of mechanism. However, the economic assessment could be used to inform the (voluntary) decisions taken by the members of the DSC and to highlight the distortions caused by non-cooperative behaviors. The analysis can be also used to highlight the importance of water trading, as implemented in Australia and the US, as a mechanism to enhance efficiency of water scarcity management.

\section{Conclusions}

Further research can expand the modeling framework assembled for the analysis shown in this paper. One obvious extension is the inclusion of a hydrological module. Related micro- and macroeconomic models offer valuable information on the costs of irrigation restrictions and the distribution thereof; yet, a first measure of cost-effectiveness demands a hydrological model that quantifies and localizes physical water flows in a way that accounts for system dynamics (e.g., riveraquifer, return flows, etc.). Hydrological modeling also provides the basic information to measure the environmental benefits that can be obtained from enhanced water flows through complementary non-market valuation methods. This offers a first measure of efficiency that could be used to better inform decision-making, within the cost-effectiveness rationale that governs EU water policy. As a next step, the authors intend to combine the economic models presented here with the hydrological model currently used to inform drought management in the Po River Basin to develop a modular hydro-economic model comprising sound micro- and macroeconomic principles.

Connecting multiple models inevitably amplifies uncertainty, but there are ways to limit this impact (Pindyck 2015). In the modular approach used in this research, accuracy can be enhanced by minimizing uncertainty along the different models involved (Ekström et al. 2013). In the case of the microeconomic model, alternative functional forms (instead of Cobb-Douglas) and methods to find tangency points along the frontier (instead of projection) could be explored in order to reduce calibration errors and improve the model's predictive capacity. Additional/ alternative attributes could also be explored for the same purpose - although this is ultimately constrained by data availability in the case study area. In the macroeconomic model, a more detailed temporal dimension may be included to also consider the duration of the drought.

Finally, researchers need to make policy-makers aware of the limitations of models and of what can and cannot be inferred from them. Opinions and debates among experts and stakeholders, despite the degree of subjectivity they bring to the decision-making processes, are still much needed in order to interpret and elaborate 
model specifications and outcomes. In turn, this interaction can help scientists to address some model limitations and improve its accuracy and predictive capacity.

\section{Acknowledgments}

This research has received funding from the EU's Horizon 2020 Research and Innovation Programme under the Marie Skłodowska-Curie grant agreement No 660608 (WATER INCENT — Economic Instruments for Sustainable Water Management in Water Scarce and Drought Prone Irrigated Areas), and from the EU's Seventh Framework Program under grant agreement No 308438 (ENHANCE - Enhancing risk management partnerships for catastrophic natural disasters in Europe). This research has also received funding from the AXA Research Fund through the Post-Doctoral Fellowships Campaign 2015.

\section{Appendix A. MRIA Model - List of Variables and Definition}

\begin{tabular}{ll}
\hline Endogenous Variables \\
\hline $\mathbf{x}_{r, t}[g]$ & Column vector of production of sector $g$ in region $r$ in time period $t$. \\
$\mathbf{s}_{r, t}[p]$ & Column vector of supply of product $p$ in region $r$ in time period $t$. \\
$\mathbf{u}_{r, t}[p]$ & Column vector of intermediate use for product $p$ in region $r$ in time period $t$. \\
$\mathbf{f}_{r, t}[p]$ & Column vector of Final demand for product $p$ in region $r$ in time period $t$. \\
$\mathbf{e}_{r, t}^{E U}[p]$ & Column vector of export to the EU regions for product $p$ in region $r$ in time period $t$. \\
$\omega_{r, t}[p]$ & Additional imports needed to satisfy excess demand given the regional supply capacity \\
& for product $p$ in region $r$ in time period $t$. \\
\hline
\end{tabular}

Exogenous variables and Parameters

$\mathbf{C}_{r}[p, g] \quad$ Regional supply matrix (in coefficients) of sector $i$ in region $r$ producing product $p$. This matrix is also known as the product mix matrix.

$\mathbf{B}_{r}[p, g] \quad$ Regional use matrix (in coefficients) of sector $i$ in region $r$ using product $p$ from region $r$.

$\mathbf{x}_{r, t}^{\max }[i] \quad$ Column vector of maximal production capacity of sector $i$ in region $r$ in time period $t$.

$\nu_{r, t}[p] \quad$ Column vector of reconstruction demand for product $p$ in region $r$ in time period $t$.

$\mathbf{e}_{r, t}^{\text {world }}[p] \quad$ Column vector of export to the rest of the world for product $p$ from region $r$ in time period $t$.

$\mathbf{m}_{r}^{E U}[p] \quad$ Import from other EU regions by $r$ for product $p$ in the base year 2000 .

$\mathbf{m}_{r}^{\text {world }}[p]$ Import from the rest of the world by region $r$ for product $p$ in the base year 2000 .

$\mathbf{T}_{s}[r, p] \quad$ The trade matrix (in coefficients) of products used in region $s$ and demanded from region $r$. These trade vectors are derived from trade data of the year 2000 .

$\mu_{r}[p] \quad$ The European import share for product $p$ demanded from region $r$.

$\eta_{r}[p] \quad$ The total import share (EU + world) for product $p$ demanded from region $r$.

$\delta \quad$ Regional maximum capacity parameter. This parameter determines to what extent all possible maximum production capacities of different industries can be added up to a regional production capacity. 
Appendix A. (Continued)

Exogenous variables and Parameters

$\overline{\sigma_{r, t}[g] \quad \text { Vector of inoperability of sector } i \text { in region } r \text { in time period } t \text {. The inoperability is a ratio }}$ between 0 and 1.

$\mathbf{y}_{r, t}[g] \quad$ Vector of value added for sector $i$ in region $r$ in time period $t$.

$\mathrm{i} \quad$ The summation column vector of $i$ sectors

I The identity matrix

Notes: The dimensions of vectors and matrices are presented within straight brackets.

\section{Appendix B. MRIA Model - Supply-Use Table}

$\mathbf{R}$

$\mathrm{S}$

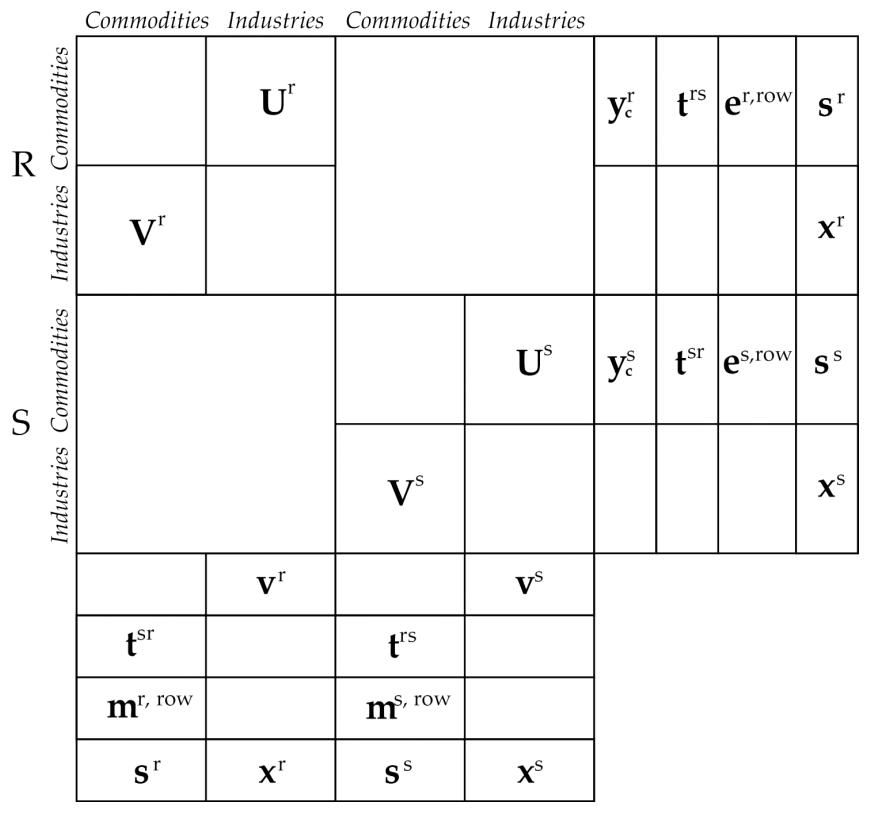

\section{References}

Adamson, D and A Loch (2014). Possible negative feedbacks from "gold-plating” irrigation infrastructure. Agricultural Water Management, doi: 10.1016/j.agwat.2013. 09.022.

Adamson, D, T Mallawaarachchi and J Quiggin (2007). Water use and salinity in the Murray-Darling Basin: A state-contingent model. Australian Journal of Agricultural and Resource Economics, 51, 263-281. 
Afriat, S (1967). The construction of a utility function from expenditure data. International Economic Review, 8, 67-77.

Amador, F, JM Sumpsi and C Romero (1998). A non-interactive methodology to assess farmers' utility functions: An application to large farms in Andalusia, Spain. European Review Agricultural Economics, 25, 92-102, doi: 10.1093/erae/25.1.92.

André, FJ, I Herrero and L Riesgo (2010). A modified DEA model to estimate the importance of objectives with an application to agricultural economics. Omega, Empirical Research in the EU Banking Sector and the Financial Crisis, 38, 371-382, doi: 10.1016/j.omega.2009.10.002

André, FJ and L Riesgo (2007). A non-interactive elicitation method for non-linear multiattribute utility functions: Theory and application to agricultural economics. European Journal of Operational Research, 181, 793-807, doi: 10.1016/j. ejor.2006.06.020.

Baghersad, M and CW Zobel (2015). Economic impact of production bottlenecks caused by disasters impacting interdependent industry sectors. International Journal of Production Economics, 168, 71-80, doi: 10.1016/j.ijpe.2015.06.011.

Bergevoet, RHM, CJM Ondersteijn, HW Saatkamp, CMJ van Woerkum and RBM Huirne (2004). Entrepreneurial behaviour of dutch dairy farmers under a milk quota system: Goals, objectives and attitudes. Agricultural System, 80, 1-21, doi: 10.1016/j. agsy.2003.05.001.

Berrittella, M, AY Hoekstra, K Rehdanz, R Roson and RSJ Tol (2007). The economic impact of restricted water supply: A computable general equilibrium analysis. Water Research, 41, 1799-1813, doi: 10.1016/j.watres.2007.01.010.

Binswanger, HP (1982). Empirical estimation and use of risk preferences: Discussion. American Journal of Agricultural Economics, 64, 391-393, doi: 10.2307/1241154.

Bogra, S, BR Bakshi and R Mathur (2016). A water-withdrawal input-output model of the Indian economy. Environmental Science Technology, 50, 1313-1321, doi: 10.1021/ acs.est.5b03492.

Bosello, F, RJ Nicholls, J Richards, R Roson and RSJ Tol (2012). Economic impacts of climate change in Europe: Sea-level rise. Climate Change, 112, 63-81.

Calliari, E (2011). Ordinary and extraordinary tools for managing drought. The 2003 and 2006/2007 events in the Po river basin. (Master's thesis). Università Commerciale Luigi Bocconi, Milano (Italy).

Calzadilla, A, K Rehdanz and RSJ Tol (2011). The GTAP-W model: Accounting for water use in agriculture (Kiel Working Paper No. 1745). Kiel Institute for the World Economy.

Cambridge Econometrics (2008). Regional production, investment and consumption in Europe for the year 2000 (Database). Cambridge Econometrics.

Carrera, L, G Standardi, F Bosello and J Mysiak (2015). Assessing direct and indirect economic impacts of a flood event through the integration of spatial and computable general equilibrium modeling. Environmental Modelling Software, 63, 109-122, doi: 10.1016/j.envsoft.2014.09.016.

Chambers, RG and J Quiggin (2000). Uncertainty, Production, Choice, and Agency: The State-Contingent Approach, 1st ed. Cambridge; New York: Cambridge University Press. 
Chung, E-S and KS Lee (2009). Prioritization of water management for sustainability using hydrologic simulation model and multicriteria decision making techniques. Journal of Environmental Management, 90, 1502-1511, doi: 10.1016/j.jenvman.2008.10.008.

Ciscar, J-C, A Iglesias, L Feyen, L Szabó, D Van Regemorter, B Amelung, R Nicholls, P Watkiss, OB Christensen and R Dankers (2011). Physical and economic consequences of climate change in Europe. Proceeding of the National Academy of Science, 108, 2678-2683.

Coppola, E, M Verdecchia, F Giorgi, V Colaiuda, B Tomassetti and A Lombardi (2014). Changing hydrological conditions in the Po basin under global warming. Science of the Total Environmental, 493, 1183-1196, doi: 10.1016/j.scitotenv.2014.03.003.

Darwin, R, ME Tsigas, J Lewandrowski and A Raneses (1995). World Agriculture and Climate Change: Economic Adaptations (Agricultural Economics Reports No. 33933). United States Department of Agriculture, Economic Research Service.

Delforce, RJ and JB Hardaker (1985). An experiment in multiattribute utility theory. Australian Journal of Agricultural Resource Economics, 29, 179-198, doi: 10.1111/ j.1467-8489.1985.tb00443.x.

Diewert, WE (1973). Afriat and revealed preference theory. The Review Economics Studies, 40, 419-425.

Dixon, PB, MT Rimmer and G Wittwer (2011). Saving the Southern Murray-Darling basin: The economic effects of a buyback of irrigation water. Economics Record, 87, 153-168, doi: 10.1111/j.1475-4932.2010.00691.x.

Duarte, R, J Sánchez-Chóliz and J Bielsa (2002). Water use in the Spanish economy: An input-output approach. Ecological Economics, 43, 71-85, doi: 10.1016/S0921-8009 (02)00183-0.

Dutch Ministry of Infrastructure and the Environment (2007). Interregional Freight. Data for Years from 2000-2004 (Database). Amsterdam, the Netherlands.

EC (2012). EU blueprint to Safeguard Europe's Water Resources (Communication No. COM(2012) 673 final). European Commission, Brussels (Belgium).

EC (2000). Water Framework Directive 2000/60/EC, Council Directive.

Edgeworth, FY (1881). Mathematical Psychics; An Essay on the Application of Mathematics to the Moral Sciences. London: C.K. Paul.

EEA (2009). Water resources across Europe - confronting water scarcity and drought (Report No. 2/2009). European Environment Agency, Copenhagen, Denmark.

Ekström, M, N Kuruppu, RL Wilby, HJ Fowler, FHS Chiew, S Dessai and WJ Young (2013). Examination of climate risk using a modified uncertainty matrix framework - Applications in the water sector. Global Environmental Change, 23, 115-129, doi: 10.1016/j.gloenvcha.2012.11.003.

ER Statistica (2014). Statistiche sulle produzioni agricole vegetali [Online Database]. Stat. Reg. Emilia Romagna. Available at: http://statistica.regione.emilia-romagna.it/ [10 April 2017].

Eurostat (2016). Eurostat Database [WWW Document]. Eurostat Database. URL http:// epp.eurostat.ec.europa.eu/portal/page/portal/statistics/themes [5 October 2013].

Eurostat (2009a). National use and supply tables. [WWW Document]. Eurostat Database. ec.europa.eu/eurostat [19 September 2016]. 
Eurostat (2009b). International trade in services. Data for years from 2000 to 2004. [WWW Document]. Eurostat Database. ec.europa.eu/eurostat [19 September 2016].

Feenstra, RC, RE Lipsey, H Deng, AC Ma and H Mo (2005). World Trade Flows: 19622000, Working Paper No. 11040. National Bureau of Economic Research.

Feldman, A (1992). Systems Analysis Applications at the Hydrologic Engineering Center (Report). US Army Corps of Engineers, David, US.

Girard, C, M Pulido-Velazquez, J-D Rinaudo, C Pagé and Y Caballero (2015). Integrating top-down and bottom-up approaches to design global change adaptation at the river basin scale. Global Environmental Change, 34, 132-146, doi: 10.1016/j.gloenvcha.2015.07.002.

Gómez-Limón, JA, C Gutiérrez-Martín and L Riesgo (2016). Modeling at farm level: Positive Multi-Attribute Utility Programming. Omega, doi:10.1016/j.omega.2015. 12.004 .

Gómez-Limón, JA and L Riesgo (2004). Water pricing: Analysis of differential impacts on heterogeneous farmers. Water Resource Research, 40, 1-12, doi: 10.1029/ 2003WR002205.

González, JF (2011). Assessing the macroeconomic impact of water supply restrictions through an input-output analysis. Water Resource Management, 25, 2335-2347, doi: 10.1007/s11269-011-9811-4.

Grames, J, A Prskawetz, D Grass, A Viglione and G Blöschl (2016). Modeling the interaction between flooding events and economic growth. Ecological Economics, 129, 193-209, doi: 10.1016/j.ecolecon.2016.06.014.

Graveline, N (2016). Economic calibrated models for water allocation in agricultural production: A review. Environmental Modelling Software, 81, 12-25, doi: 10.1016/j. envsoft.2016.03.004.

GU (1994). Legge 5 gennaio 1994, n. 36 Disposizioni in materia di risorse idriche, Law.

Gutiérrez-Martín, C and CM Gómez (2011). Assessing irrigation efficiency improvements by using a preference revelation model. Span: Journal of Agricultural Research, 9, 1009-1020, doi: 10.5424/sjar/20110904-514-10.

Gutiérrez-Martín, C, CD Pérez-Blanco, CM Gómez and J Berbel (2014). Price volatility and water demand in agriculture. A case study of the guadalquivir river basin (Spain). In Economics of Water Management in Agriculture. Bournaris, T, J Berbel, B Manos, D Viaggi (eds.), pp. 319-348, Boca Raton, US.

Harou, JJ, M Pulido-Velazquez, DE Rosenberg, J Medellín-Azuara, JR Lund and RE Howitt (2009). Hydro-economic models: Concepts, design, applications, and future prospects. Journal of Hydrology, 375, 627-643, doi: 10.1016/j.jhydrol.2009.06.037.

Hazell, PBR and PL Scandizzo (1977a). Farmers' expectations, risk aversion, and market equilibrium under risk. Amercian Journal of Agricultural Economics, 59, 204-209, doi: $10.2307 / 1239629$.

Hazell, PBR and PL Scandizzo (1977b). Farmers' expectations, risk aversion, and market equilibrium under risk. Amercian Journal Agricultural Economics, 59, 204-209, doi: $10.2307 / 1239629$.

Heckelei, T and W Britz (2005). Models based on positive mathematical programming: State of the art and futher extensions, in Proceedings of the 89th EAAE Seminar. Presented at the 89th EAAE Seminar, Parma, Italy, pp. 48-73. 
Heckelei, T, W Britz and Y Zhang (2012). Positive mathematical programming approaches - recent developments in literature and applied modeling. Bio-based and Applied Economics.

Heinz, I, M Pulido-Velazquez, JR Lund and J Andreu (2007). Hydro-economic modeling in river basin management: Implications and applications for the european water framework directive. Water Resource Management, 21, 1103-1125, doi: 10.1007/ s11269-006-9101-8.

Hertel, TW (1997). Global Trade Analysis: Modeling and Applications. Cambridge: Cambridge University Press.

Houthakker, HS (1950). Revealed preference and the utility function. Economica, 17, 159-174.

Inada, K-I (1963). On a two-sector model of economic growth: comments and generalization. The Review of Economics Studies, 30, 119-127.

INEA (2015). RICA database. [Online Database]. Rete Inf. Contab. Agric. RICA. Available at: http://www.rica.inea.it/public/it/index.php.

IPCC (2014). IPCC Fifth Assessment Report (AR5) (No. WGII). Intergovernmental Panel on Climate Change, Geneva (Switzerland).

ISMEA (2014). Rete di Rilevazione Prezzi ISMEA [Online Database]. Prezzi Mensili ISMEA. Available at: http://www.ismea.it/flex/cm/pagesServeBLOB.php/L/IT/ IDPagina/27.

ISTAT (2013). Atlante dell'agricoltura Italiana (Report No. $6^{\circ}$ Censimento Generale dell'Agricoltura). Istituto Nazionale di Statistica.

Just, RE (1975). Risk aversion under profit maximization. Amercian Journal of Agriculturla Economcis, 57, 347-352, doi: 10.2307/1238513.

Koks, EE, L Carrera, O Jonkeren, JCJH Aerts, TG Husby, M Thissen, G Standardi and J Mysiak (2015). Regional disaster impact analysis: Comparing Input-Output and Computable General Equilibrium models. Natural Hazards and Earth System Sciences Discuss, 3, 7053-7088, doi: 10.5194/nhessd-3-7053-2015.

Koks, EE and M Thissen (2016). A multiregional impact assessment model for disaster analysis. Economic System Research, 28, 429-449, doi: 10.1080/09535314.2016. 1232701.

Läpple, D and H Kelley (2013). Understanding the uptake of organic farming: Accounting for heterogeneities among Irish farmers. Ecological Economics, Transaction Costs and Environmental Policy, 88, 11-19, doi: 10.1016/j.ecolecon.2012.12.025.

Lenzen, M, D Moran, K Kanemoto and A Geschke (2013). Building Eora: A global multiregion input-output database at high country and sector resolution. Economcis Systems Research, 25, 20-49.

Llop, M (2008). Economic impact of alternative water policy scenarios in the Spanish production system: An input-output analysis. Ecological Economics, 68, 288-294, doi: 10.1016/j.ecolecon.2008.03.002.

Lynne, GD (1995). Modifying the neo-classical approach to technology adoption with behavioral science models. Journal of Agricultural and Applied Economics, 27, 67-80, doi: 10.1017/S107407080001960X.

Maass, A, MM Hufschmidt, R Dorfman, Jr, HATSA Marglin and GM Fair (1962). Design of Water-Resource Systems: New Techniques for Relating Economic Objectives, 
Engineering Analysis, and Governmental Planning. Cambridge, Mass: Harvard University Press.

Mallawaarachchi, T, S Hone, D Adamson, Y Alasebu, M Oliver, P Kokic, J Quiggin and P Gooday (2008). Reduced water availability Impacts on agricultural activities and regional economies in the Murray-Darling Basin (ABARE client report prepared for the Murray-Darling Basin Commission). Australian Bureau of Agricultural and Resource Economics (ABARE), Canberra, Australia.

Marshall, GR (2013). Transaction costs, collective action and adaptation in managing complex social-ecological systems. Ecological Economics, 88, 185-194, doi: 10.1016/j.ecolecon.2012.12.030.

McCarl, BA (1982). Cropping activities in agricultural sector models: A methodological proposal. Amercian Journal of Agricultural Economics, 64, 768-772, doi: 10.2307/ 1240588.

Medri, S, S Venturini and S Castellari (2013). Overview of Key Climate Change Impacts, Vulnerabilities and Adaptation Action in Italy (SSRN Scholarly Paper No. ID 2317832). Social Science Research Network, Rochester, NY.

Miller, RE and PD Blair (2009). Input-Output Analysis: Foundations and Extensions, 2nd eds. Cambridge England, New York: Cambridge University Press.

Mysiak, J, L Carrera, M Amadio, P Blanco, C Dionisio and S Santato (2014). Development of MSPs in the Po River Basin District. Controlled floods on agricultural and scarcely developed rural land (MSP-F) and Managing severe drought spells in the otherwise water-abundant river basin district (MSP-D) (Deliverable No. 7.2). Fondazione Eni Enrico Mattei.

OECD (2014). Climate Change, Water and Agriculture. Organisation for Economic Co-Operation and Development, Paris.

Oosterhaven, J and MC Bouwmeester (2016). A new approach to modeling the impact of disruptive events. Journal of Regional Science, doi: 10.1111/jors.12262.

Pérez-Blanco, CD, G Delacámara and CM Gómez (2015). Water charging and water saving in agriculture. Insights from a Revealed Preference Model in a Mediterranean basin. Environmental Modelling Software, 69, 90-100, doi: 10.1016/j.envsoft.2015. 03.006.

Pérez-Blanco, CD, G Standardi, J Mysiak, R Parrado and C Gutiérrez-Martín (2016). Incremental water charging in agriculture. A case study of the Regione Emilia Romagna in Italy. Environmental Modelling Software, 78, 202-215, doi: 10.1016/j. envsoft.2015.12.016.

Pindyck, RS (2015). The Use and Misuse of Models for Climate Policy, Working Paper No. 21097, National Bureau of Economic Research.

Poppenborg, P and T Koellner (2013). Do attitudes toward ecosystem services determine agricultural land use practices? An analysis of farmers' decision-making in a South Korean watershed. Land Use Policy, Themed Issue 1-Guest Editor Romy GreinerThemed Issue 2- Guest Editor Davide Viaggi, 31, 422-429, doi: 10.1016/j. landusepol.2012.08.007.

PRBA (2005). Attività unitaria conoscitiva e di controllo del bilancio idrico volta alla prevenzione degli eventi di magra eccezionale nel bacino idrografico del fiume Po (Report). Po River Basin Authority, Parma, Italy. 
PRBA (2003). Protocollo di Intesa (Memorandum of Understanding). Po River Basin Authority, Parma, Italy.

PRBDA (2015). Crisi idrica estate 2015 — Cabina di Regia (Cabina di Regia). Po River Basin District Authority.

Rabin, M and B Kőszegi (2007). Mistakes in choice-based welfare analysis. Amercian Economics Review, 97, 477-481.

Rabin, M and RH Thaler (2001). Anomalies: Risk aversion. Journal of Economic Perspectives, 15, 219-232, doi: 10.1257/jep.15.1.219.

Randall, A (1981). Property entitlements and pricing policies for a maturing water economy. Australian Journal of Agricultural and Resource Economics, 25, 195-220, doi: 10.1111/j.1467-8489.1981.tb00398.x.

Rausser, GC and J Yassour (1981). Multiattribute utility analysis: The case of filipino rice policy. Amercian Journal of Agricultural Economics, 63, 484-494, doi: 10.2307/ 1240539.

Rodrigues, GC, P Paredes, JM Gonçalves, I Alves and LS Pereira (2013). Comparing sprinkler and drip irrigation systems for full and deficit irrigated maize using multicriteria analysis and simulation modeling: Ranking for water saving vs. farm economic returns. Agricultural Water Management, 126, 85-96, doi: 10.1016/j. agwat.2013.05.005.

Samuelson, PA (1938). A note on the pure theory of consumer's behaviour. Economica, 5, 61-71, doi: 10.2307/2548836.

Schmidt, G. and Benítez-Sanz, C., 2012. Topic report on: Assessment of Water Scarcity and Drought aspects in a selection of European Union River Basin Management Plans (Study by Intecsa-Inarsa for the European Commission under contract "Support to the implementation of the Water Framework Directive (2000/60/EC)” No. 070307/2011/600310/SER/D.2). European Commission, Brussels, Belgium.

SEO (2010). Marketing Information Data Transfer database, Regional Flights, Business and First Class (Database). SEO, Amsterdam, the Netherlands.

Singh, A (2012). An overview of the optimization modeling applications. Journal of Hydrology, 466-467, 167-182, doi: 10.1016/j.jhydrol.2012.08.004.

Strosser, P, T Dworak, PGA Delvaux, M Berglund, G Schmidt, J Mysiak, M Kossida, I Iacovides and V Ashton (2012). Gap Analysis of the Water Scarcity and Droughts Policy in the EU (European Commisison Directorate General Environment, Final report Tender No. ENV.D.1/SER/2010/0049).

Thissen, M, F van Oort, D Diodato and A Ruijs (2014). Regional Competitiveness and Smart Specialization in Europe: Place-based Development in International Economic Networks. Cheltenham, UK; Northampton, MA, USA: Edward Elgar Pub.

UN (2016). The United Nations World Water Development Report 2016 (Report). United Nations.

UNESCO (1999). UNESCO convention concerning the protection of the World Cultural and Natural Heritage (Report No. 23 COM). UNESCO, Marrakesh (Morocco).

Varian, HR (2012). Revealed preference and its applications. The Economics Journal, 122, 332-338, doi: 10.1111/j.1468-0297.2012.02505.x.

Varian, HR (2006). Revealed preference. In Samuelsonian Economics and the Twenty-First Century. M Szenberg, L Ramrattan and AA Gottesman (eds.), New York, US, p. 382. 
Vezzoli, R, P Mercogliano, S Pecora, AL Zollo and C Cacciamani (2015). Hydrological simulation of Po River (North Italy) discharge under climate change scenarios using the RCM COSMO-CLM. Science of Total Environment, 521-522, 346-358, doi: 10.1016/j.scitotenv.2015.03.096.

Wang, Y, H Xiao and R Wang (2009). Water scarcity and water use in economic systems in Zhangye City, Northwestern China. Water Resource Management, 23, 2655-2668, doi: 10.1007/s11269-009-9401-X.

Wan, L, W Cai, Y Jiang and C Wang (2016). Impacts on quality-induced water scarcity: Drivers of nitrogen-related water pollution transfer under globalization from 1995 to 2009. Environmental Research Letters, 11, 074017, doi: 10.1088/1748-9326/11/7/ 074017.

Zhao, X, J Liu, Q Liu, MR Tillotson, D Guan and K Hubacek (2015). Physical and virtual water transfers for regional water stress alleviation in China. Proceedings of the National Academy Science, 112, 1031-1035, doi: 10.1073/pnas.1404130112. 